\title{
FAST Mast Structural Response to Axial Loading: Modeling and Verification
}

\author{
Norman F. Knight, Jr. \\ General Dynamics Information Technology, Herndon, Virginia \\ Kenny B. Elliott ${ }^{\dagger}$, Justin D. Templeton ${ }^{\ddagger}$ \\ NASA Langley Research Center, Hampton, Virginia \\ Kyongchan Song ${ }^{\S}$ \\ ATK Space Division, Hampton, Virginia \\ Jeffery T. Rayburn ${ }^{* *}$ \\ NASA Marshall Space Flight Center, Huntsville, Alabama
}

\begin{abstract}
The International Space Station's solar array wing mast shadowing problem is the focus of this paper. A building-block approach to modeling and analysis is pursued for the primary structural components of the solar array wing mast structure. Starting with an ANSYS $^{\circledast}$ finite element model, a verified MSC.Nastran ${ }^{\text {TM }}$ model is established for a single longeron. This finite element model translation requires the conversion of several modeling and analysis features for the two structural analysis tools to produce comparable results for the single-longeron configuration. The model is then reconciled using test data. The resulting MSC.Nastran ${ }^{m i}$ model is then extended to a single-bay configuration and verified using single-bay test data. Conversion of the MSC. Nastran ${ }^{\text {MM }}$ single-bay model to Abaqus ${ }^{\text {TM }}$ is also performed to simulate the elastic-plastic longeron buckling response of the single bay prior to folding.
\end{abstract}

\section{Introduction}

The International Space Station (ISS), shown in Fig. 1, has eight sets of solar array blankets. Each set is referred to as a Solar Array Wing (SAW) supported by a center retractable four-longeron mast. Each mast structure has 32 bays based on the Folding Articulated Square Truss (FAST) mast design developed by ATK Aerospace Systems in Goleta, CA (formerly ABLE Engineering, Inc.). Each mast can be deployed and stowed as needed during ISS operations. Each mast has a 30.4-inch square cross-section with a stowed length of 90 inches and a deployed length of 1296 inches, as indicated in Fig. 2. Background information on the FAST mast configuration and its development is provided in Refs. 1-7.

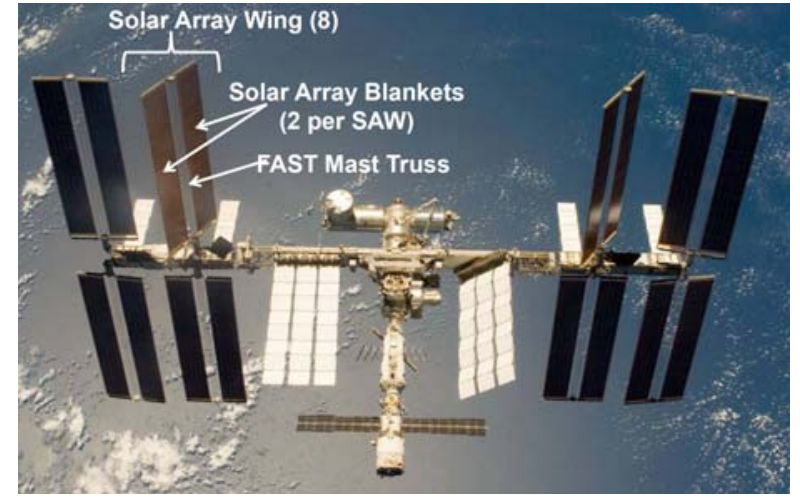

Figure 1. ISS FAST mast trusses and solar array wings.

\footnotetext{
* Principal Subject Matter Expert, Structural Mechanics. Fellow AIAA, Fellow ASME.

${ }^{\dagger}$ Aerospace Engineer, Systems Integration \& Test Branch. Member AIAA.

${ }^{\ddagger}$ Aerospace Engineer, Systems Integration \& Test Branch. Member AIAA.

$\S$ Structural Analyst. Member AIAA.

${ }^{* *}$ Aerospace Technologist, Strength and Life Assessment Team Lead.
} 
During routine ISS operations, it is possible for portions of one or more SAW masts to experience shadowing. Mast shadowing has two potential sources: self shadowing and adjacent-array shadowing. Self-shadowing is when a SAW is positioned such that it leads to shadowing of its own mast structure. Adjacent-array shadowing is when an outboard SAW casts a shadow on its adjacent inboard SAW mast. The resulting asymmetric thermal loads combined with operational mechanical loads have the potential to exceed design limits for the critical axial loads. Currently, the ISS Program is managing the thermal buckling threat through careful operations planning. This limits the ISS operations and causes potential conflicts between optimum SAW configuration, nominal events, off-nominal events, and safe operations.

The critical axial load design limits were defined using results obtained from the original FAST mast development based on single-bay axial compression tests of an individual longeron performed at room temperature. Due to the potential for longeron shadowing, the influence of combined thermal and mechanical loadings on the longeron critical axial load needed to be assessed.

An independent assessment of the combined thermal and mechanical loadings using a 4-bay FAST mast configuration has been performed by the NASA Engineering and Safety Center (NESC) to assess the mast strength and stability under asymmetric thermal loading to ensure proper engineering rationale is being used to set safe operational limits. Testing of a 4-bay configuration was performed using the 25-foot Space Simulation Facility at the NASA Jet Propulsion Laboratory (JPL), see Fig. 3 and Refs. 8-10. As part of the assessment and prior to the JPL testing, limited single-longeron and single-bay axial loading tests were performed by ATK. ${ }^{10}$

Analysis of the mast's response is a multidisciplinary effort involving thermal and structural disciplines. The focus of the NESC assessment is the development of thermal and mechanical analytical models that predict the behavior of the mast during a thermal shadowing event. These 'predictive' models are then used to assess the conservatism in the engineering models currently used to assess the response of the mast to a thermal shadowing event. Originally, a traditional approach to model validation was adopted for the NESC assessment. That is, the models were calibrated to match the results of a combined thermal/mechanical test on a sub-assembly of four bays, and the final models are declared 'validated'. ${ }^{8-10}$ The structural response was determined by ATK ${ }^{10}$ using a finite element model developed for ANSYS ${ }^{\circledR 11}{ }^{\dagger}$, and overall good correlation was obtained for selected thermocouple, displacement, and strain gage measurements at peak loading conditions during the JPL tests. ${ }^{9,10}$ However, several questions surfaced about the use of these models. The first question concerned the uncertainty associated with the 'validated' model's predictions, and insufficient information was available to answer this question. This question of uncertainty quantification became particularly important since these new models are to be 'predictive', and normal conservative assumptions are not adopted. The second question concerned whether the models are valid only for the calibrated test (point calibration rather than a response history). Predicting on-orbit behavior is an extrapolation, and without the protection of conservative assumptions within the analytical predictions, the on-orbit extrapolation may lead to the wrong conclusions.

To address these questions, a strategy incorporating the principles of the ASME Standard V\&V 10-2006 ${ }^{12}$ was developed in which a building-block approach to model development was adopted. The modeling progresses from

${ }^{+1}$ ANSYS is a registered trademark of ANSYS, Inc. 
simple components up through the full assembly. At each modeling step, the models are verified, calibrated, and validated, and estimates of the model uncertainty are included at each step. Additional single-longeron and singlebay axial loading tests were also performed at NASA Langley after the JPL testing to assess the stiffness, buckling, and folding characteristics of the structure and provide additional data for the calibration and validation. ${ }^{13}$ This additional testing included tension and compression load cycling to evaluate potential variability in the tension and compression stiffness response. The goal is to produce a model that predicts the response to a thermal shadowing event including an estimate of the uncertainty in that prediction.

The building blocks employed in this assessment are derived based on a flow down of structural elements. Understanding the response of the mast (assembly) is dependent on understanding the response of a single bay (unit), that is in-turn dependent on understanding the response of the components of a single bay. The four-bay ANSYS $^{\circledR}$ finite element model can be leveraged to provide the basis for these building-block elements. The singlelongeron configuration is the first step in the building-block modeling approach. Once this step is complete, those modeling details are used to create a single-bay model that includes the addition of rigid battens, flex battens, and diagonal cable components. The next level is the subassembly of four bays followed by the full 32-bay configuration. Unfortunately, resource and program constraints required the use of MSC Nastran ${ }^{\text {TM } 14 \neq}$ as the modeling tool. Therefore, the building-blocks extracted from the ANSYS ${ }^{\circledR}$ finite element model had to be converted to MSC Nastran $^{\mathrm{TM}}$ finite element model of comparable accuracy.

This paper presents the modeling and conversion process employed to transform the ANSYS ${ }^{\circledR}$ finite element model of the first two building blocks, the single longeron and single bay, to a MSC Nastran ${ }^{\mathrm{TM}}$ finite element model. The paper also identifies modeling and analysis differences associated with each analysis tool. First, the FAST mast structural components are introduced, and their finite element modeling is described. Next, the analysis approach for model translation and verification is described. Then, correlation results are presented and discussed for the single-longeron and single-bay testing performed at NASA Langley to generate calibration and validation data.

\section{FAST Mast Structural Configuration}

The FAST mast structure is comprised of 32 bays each having a square cross section as shown in Fig. 2. A typical single bay is shown in Fig. 4 with its main structural components identified. Each bay includes five mechanical components: four pairs of upper and lower longerons, eight two-piece rigid battens, four flexible (or flex) battens, sixteen diagonal cables, and twelve mechanical joints (eight corner joints and four elbow joints). Each component is briefly described in the appendix including the finite element modeling assumptions used for each component.

The primary structural members of the 32-bay FAST mast configuration are the four longerons with each longeron having 32 longeron pairs (or 64 longeron segments) along the 32-bay mast. Longerons in the first twenty bays and the last (or tip) bay are tapered longerons; while longerons in bays 21 through 31 are straight longerons. Each longeron is made from 6061-T6 aluminum. Each longeron segment is 20.25 inches long from end to end, and the overall 32-bay mast is 1296 inches in length (108 feet). A typical longeron segment is shown in Fig. 5. The 'tang' end of a longeron is also called a corner fitting or notched end. The 'clevis' end of a longeron is also called the elbow fitting end. These

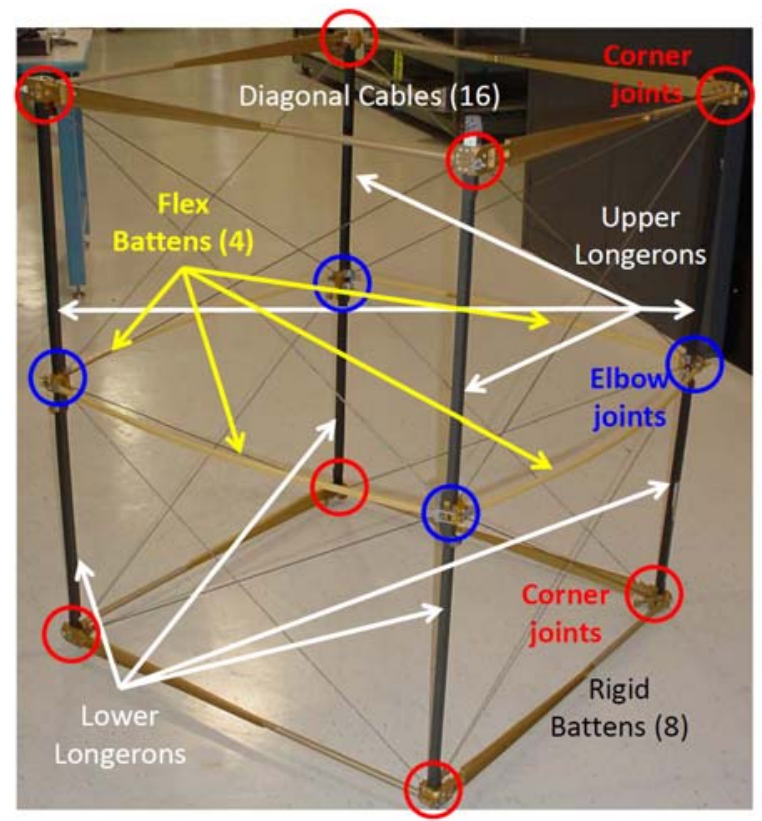

Figure 4. Single bay of the FAST mast 32-bay system and its main structural components.

\# NASTRAN is a registered trademark of NASA. 


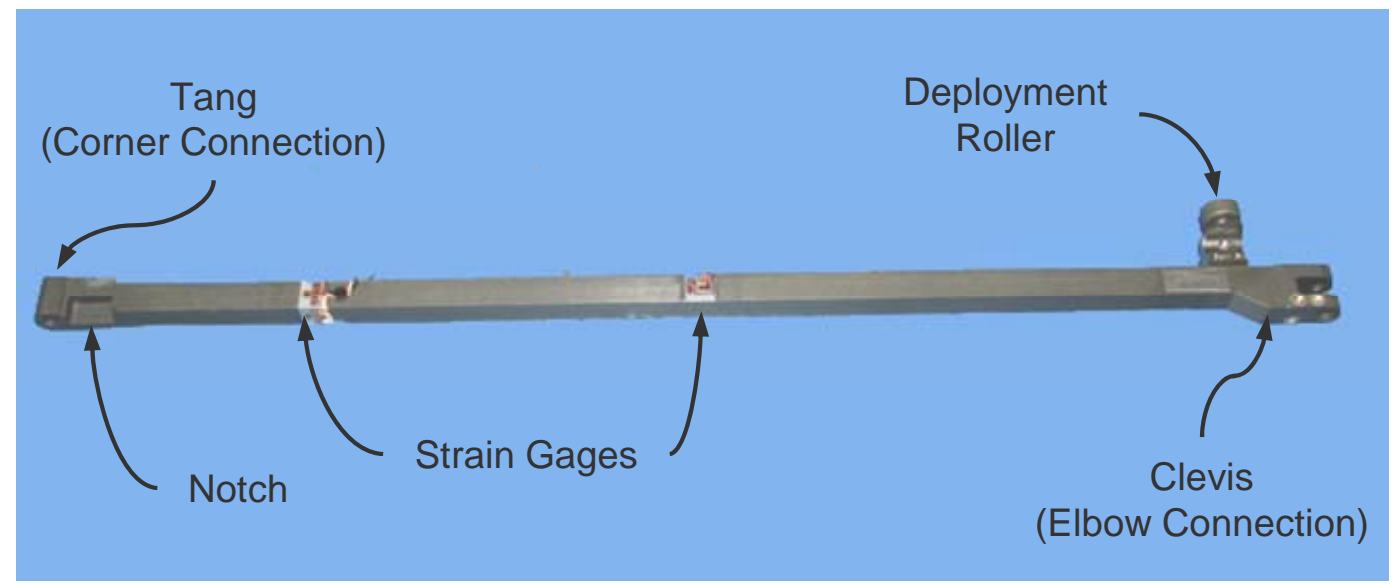

Figure 5. Typical single longeron segment.

\section{New Model Development}

To analyze the SAW mast, it is best to work using a building-block progression from components, to units, to assembly. Understanding the response of the mast (assembly) is dependent on understanding the response of a single bay (unit), that is in-turn dependent on understanding the response of the components of the bay, in particular the individual longerons.

\section{Building-Block Approach}

A basic building-block approach is employed for modeling and analysis. The building-block concept is prevalent within the product development world as well as in the structural mechanics research environment (e.g., see Refs. 15-17) and is commonly used to verify a design feature or capability by testing. A building-block approach begins with basic features and builds in complexity in a systematic, progressive manner. This process, by its very nature, is an iterative process. For example, the basic idea is to develop fundamental understanding and material characterization data using simple coupon-level testing to establish statistically relevant properties and design allowables. The number of steps in a building-block approach depends on the complexity of the structural system, the material selection, and the operating environment and loading.

Extensions of the testing building-block approach to modeling and analysis has many parallels. Yet such a modeling and analysis plan ${ }^{18}$ is usually informal and less structured than similar plans required for testing even though reliance on modeling and analysis is increasing. Such an approach permits each step in the modeling and analysis process to be verified and its influence on the overall response to be determined. In some cases, analysis guidelines have been established, tried and found true for specific configurations and loadings; in particular, for linear elastic structural analyses. However, as new materials are integrated in the design, as performance requirements increase, and as uncertainty quantification for modeling and analysis becomes necessary, analysis models of complex structures having been anchored using a building-block approach during their development will become more common. Credible, predictive analysis models are the desired end result within the scope of the modeling and analysis plan.

\section{New Model Evolution}

The first step in developing the MSC.Nastran ${ }^{\mathrm{TM}}$ model is to extract single-longeron and single-bay subcomponent models, as shown in Fig. 6, from the ATK ANSYS ${ }^{\circledR}$ model of the 4-bay FAST mast ${ }^{10}$. The ANSYS ${ }^{\circledR}$ 4-bay model had been translated by ATK to a Nastran ${ }^{\mathrm{TM}}$ bulk data file, and this Nastran ${ }^{\mathrm{TM}}$ model is the starting point for these comparative analyses. The ANSYS ${ }^{\circledR}$ and Nastran ${ }^{\mathrm{TM}}$ finite element models are used in a comparative study to identify any modeling and analysis differences using subcomponent models. When differences are evident in the predicted responses, the second step is the resolution of differences between the two analytical models, which could be traced to subtle modeling features or element formulation differences between the two analysis tools. Once the results from the two models are verified, the next level of modeling complexity is incorporated. This process

4 
continues until the results for a complete single longeron (end-fitting-to-end-fitting) are obtained. At this stage, the ANSYS $^{\circledR}$ model and a new modified Nastran ${ }^{\mathrm{TM}}$ model of a single longeron gave comparable response prediction and represented the physics of a compression-loaded single longeron. The third step involved using this modified Nastran $^{\mathrm{TM}}$ single longeron model to predict structural response to axial loading and compare the results to test. In this calibration step, modeling assumptions for the dead bands ${ }^{\S}$, load path through the mechanical joints, and joint pins are studied to determine relative sensitivities in correlating to test. The resulting model is called the reconciled Nastran ${ }^{\mathrm{TM}}$ model, which minimizes the difference between test and analysis for several metrics. ${ }^{13}$ The final step in this paper is to incorporate the modeling details and assumptions of the reconciled model into a single-bay model and to assess additional modeling assumptions needed for the new structural members associated with a single bay (i.e., multiple longerons, rigid battens, flex battens, diagonal cables). Each step in the model evolution is described in subsequent sections.

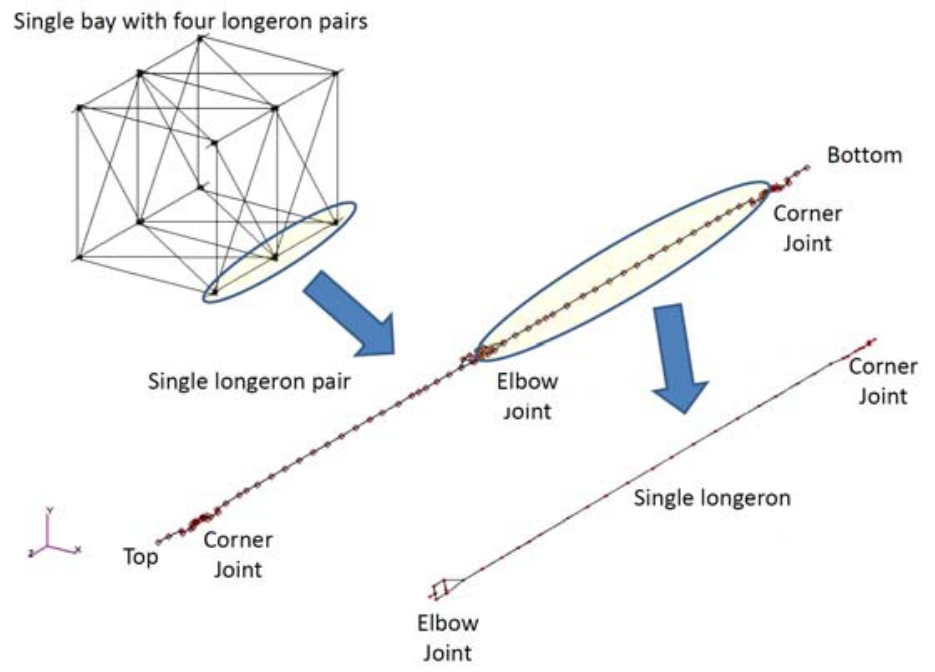

Figure 6. Single-bay model showing extracted longeron pair and single longeron.

\section{Single-Longeron Response}

The single-longeron segment extracted from the single-bay model from the ATK ANSYS ${ }^{\circledR}$ model of the 4-bay FAST mast ${ }^{10}$ is shown in Fig. 7. This single longeron model establishes the basis for the building-block approach used to develop and verify the MSC.Nastran ${ }^{\mathrm{TM}}$ single longeron model. In the building-block approach, three finite element models of this single longeron are analyzed using the two analysis tools (ANSYS ${ }^{\circledR}$ and MSC.Nastran ${ }^{\mathrm{TM}}$ ). A series of analysis test cases using different boundary conditions and modeling assumptions are analyzed and results compared for the three analysis models. Large-deflection, nonlinear analyses are performed, and load versus end displacement response curves are compared. Comparisons between the analysis results for the same structural configurations confirmed that subtle modeling details and differences exist between the two analysis tools. This first step in the building-block modeling approach for this assessment is used to validate and calibrate a MSC Nastran ${ }^{\mathrm{TM}}$ model.

\section{Modeling}

The single longeron shown in Fig. 5 exhibits a near uniform square cross section for most of its length. The region between the longeron ends is taken as 17.5 inches - called the 'middle' region as indicated in Fig. 7. This 'middle' region of a longeron is further divided into three segments: a 3.0-inch-long clevis-end segment with four beam elements, an 11.25-inch-long middle segment with twelve beam elements, and a 3.25-inch-long notched corner-end segment with four beam elements. Except for the ends, the longeron middle segment has a 0.5-inchsquare cross section for straight longerons and a 0.59-inch-square cross section for tapered longerons. The clevis end of the longeron segment is referred to as the "elbow fitting" end or simply the elbow end, while the notched end is referred to as the "corner fitting" end or simply the corner end, see Fig. 8. Each vertex of a bay has a longeron pair (i.e., upper and lower longerons) connected together through an elbow joint or fitting. Adjacent bays in the mast connect the longerons using corner joints or fittings. These mechanical joints allow the mast to be retracted (or stowed) and deployed as required for on-orbit ISS operations. ${ }^{1,2,5}$

Cross-sectional variations from the longeron square cross-sectional shape are noted at the notched corner and clevis elbow ends of the longeron, see Fig. 8. Each longeron end features special modeling considerations in order

${ }^{\S}$ The total effect of nonlinear contact stiffness combined with joint free-play is termed 'dead band'. See the appendix for further discussion. 5

American Institute of Aeronautics and Astronautics 
to simulate the pin or axle at each joint as well as the clearance within each joint. The pins or axles at the longeron ends are modeled using beam elements with very small values for the torsional constant $\mathrm{J}$ in order to simulate a 'free' pin condition or a larger value to simulate increased 'tightness' or even a 'fixed' or 'locked' pin condition. The joint fitting load paths (i.e., regions between nodes C1 and C2 and between nodes E1 and E2 and shown as green lines in Fig. 7) are modeled using three overlaid elements: two rod elements to simulate the joint dead bands due to geometric tolerances and a beam element with section properties used to represent the bending response. Modeling details of these ends are described further in the appendix.

The longeron notched and clevis ends shown in Fig. 8 are essentially the same for all longerons. The modeling of these longeron ends has the potential for causing differences in the predicted response that could be attributed to line-of-action or eccentricities, joint fitting load path modeling, and pin rotational constraints. Eccentricities in the load path are caused by longeron geometry (notched end) as well as the load introduction point on the pins in the elbow and corner joint. The longeron ends in the analysis model shown in Fig. 7 (i.e., the region between C1 and $\mathrm{C} 2$ and the region between E1 and E2) have overlaid elements to simulate tension or compression only behavior related to initial clearances or dead bands between the holes and the pins.

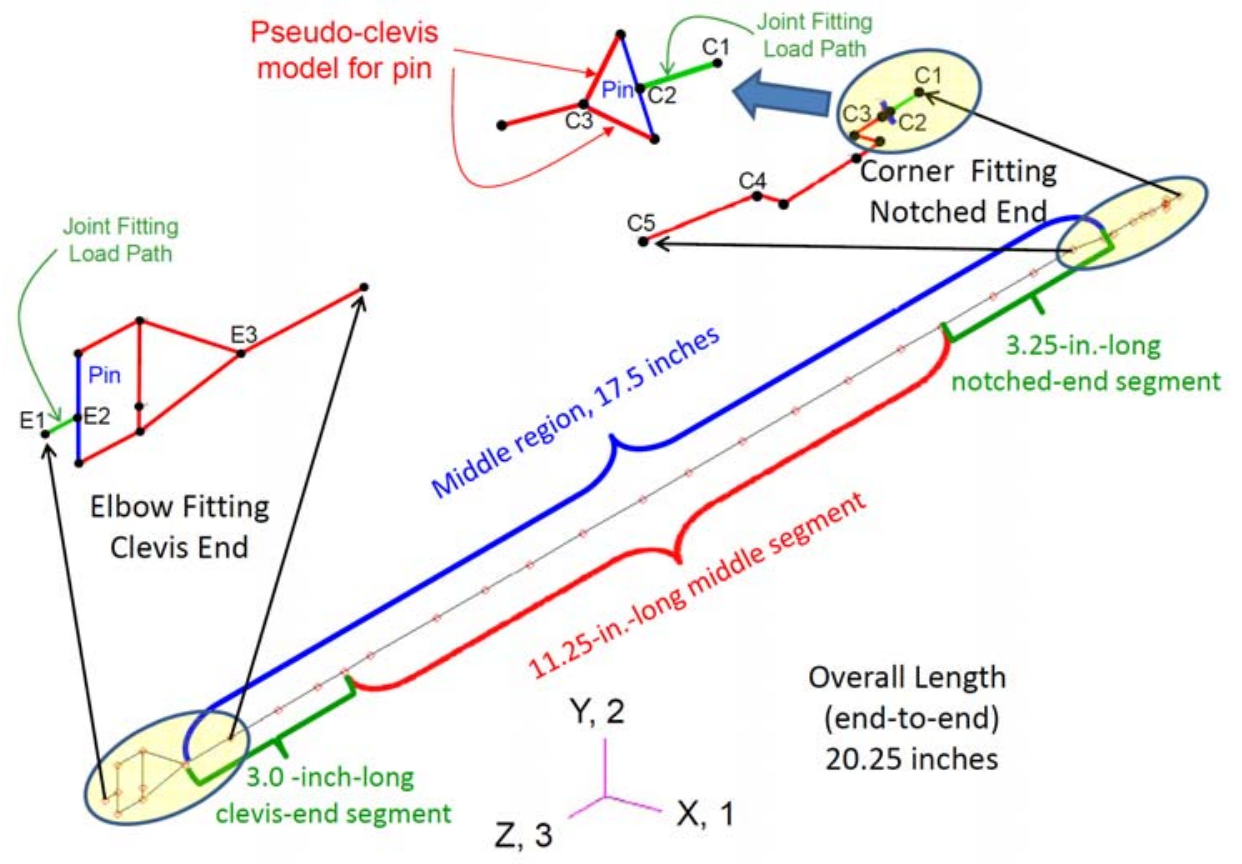

Figure 7. Node identifiers for the corner end and elbow end for the building-block study.

The ANSYS ${ }^{\circledR}$ single longeron model is originally extracted from the ATK 4-bay model. The longeron is modeled using 2-node beam elements (i.e., BEAM44 ${ }^{* * *}$ elements in ANSYS ${ }^{\circledR}$ ) with uniform cross sectional properties. The notched corner end is offset from the longeron axis using rigid elements, and a 'pseudo-clevis' model (i.e., local region that splits the longeron over a 0.2 -inch distance using rigid elements, see top center of Fig.7) is defined in order to model the pin at the corner end. The joint fitting load paths are modeled using two overlaid LINK10 ${ }^{\dagger \dagger \dagger}$ elements (one element for tension behavior and another for compression) with specified cross sectional areas (i.e., $\mathrm{A}_{\mathrm{T}}$ and $\mathrm{A}_{\mathrm{C}}$ ) and initial strains $\left(\varepsilon_{0}\right)_{\mathrm{T}}$ and $\left(\varepsilon_{0}\right)_{\mathrm{C}}$ to simulate the joint dead bands. Also included in the joint fitting load path models is an overlaid beam element with near zero cross sectional area, while the other cross sectional properties (i.e., $\mathrm{I}_{1}, \mathrm{I}_{2}, \mathrm{I}_{12}$, and $\mathrm{J}$ ) are used to 'tune' the finite element results to existing stiffness data. ATK 'tuned' the ANSYS ${ }^{\circledR}$ 4-bay model ${ }^{10}$ based on results from an ATK 3D model and the single-bay buckling tests performed during the mast original development. ${ }^{10}$

\footnotetext{
**** The BEAM44 element is a spatial 2-node beam element with axial, bending, and torsional capabilities. Cross-sectional properties may vary linearly from one end of the beam to the other along the local longitudinal axis of the beam element.

${ }^{\mathrm{HT}}$ LINK10 is a 3-D spar element having the unique feature of a bilinear stiffness matrix resulting in a uniaxial tension-only (or compressiononly) element. LINK10 has three degrees of freedom at each node: translations in the nodal $\mathrm{x}, \mathrm{y}$, and $\mathrm{z}$ directions. No bending stiffness is included. Stress stiffening and large deflection capabilities are available.
} 

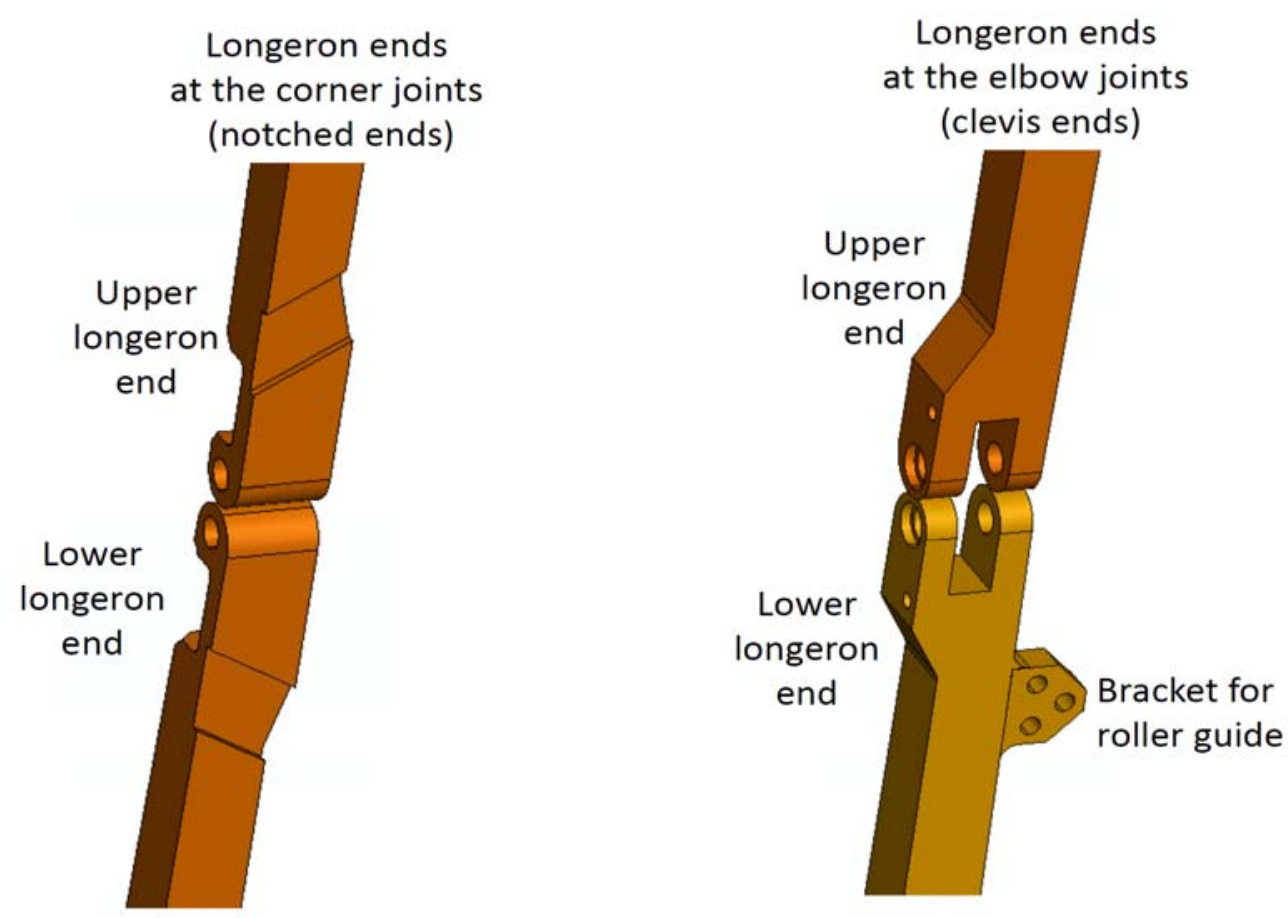

Figure 8. Longeron ends: notched or corner end (left) and clevis or elbow end (right).

The MSC.Nastran ${ }^{\mathrm{TM}}$ model of the single longeron will be referred to as the original Nastran ${ }^{\mathrm{TM}}$ model in this paper, because it is based on theATK conversion of their ANSYS ${ }^{\circledR}$ model with the following exceptions. The longeron is modeled using 2-node beam elements (i.e., CBEAM ${ }^{\ddagger \neq}$ elements in MSC.Nastran ${ }^{\mathrm{TM}}$ ), and any element translated as a CBAR ${ }^{\S \S}$ element is converted to a CBEAM element. The notch offsets and 'pseudo-clevis' offsets are modeled using $\mathrm{RBAR}^{* * * *}$ elements. The joint fitting dead bands are modeled using overlaid CGAP ${ }^{\dagger+\dagger+}$ elements having specified initial gaps and stiffness when the gap is closed. The cross sectional properties (i.e., $\mathrm{I}_{1}, \mathrm{I}_{2}, \mathrm{I}_{12}$, and $\mathrm{J}$ ) of the overlaid beam element in the joint fitting load path model are tuned to match the peak load predicted by the ANSYS ${ }^{\circledR}$ model.

During the course of comparing the results from these two models, it was realized that not all elements used in the original Nastran ${ }^{\mathrm{TM}}$ model supported large deflection analysis using solution sequence SOL106. Therefore, a modified Nastran ${ }^{\mathrm{TM}}$ model of the single longeron is developed based on the original Nastran ${ }^{\mathrm{TM}}$ single longeron model. The longeron is again modeled using 2-node beam elements (i.e., CBEAM elements in MSC.Nastran ${ }^{\mathrm{TM}}$ ). The notch offsets and 'pseudo-clevis' offsets are now modeled using very stiff beam elements instead of using RBAR elements. The overlaid CGAP elements are replaced with overlaid CROD ${ }^{\ddagger \neq \neq}$ elements for tension and compression having a specified area and a defined nonlinear elastic stress-strain curve to simulate the tension-only/compressiononly dead bands. The beam elements in the joint fitting load path regions (i.e., between nodes C1 and C2 and between nodes E1 and E2 shown in Fig. 7) have the same section properties as those in the original Nastran ${ }^{\mathrm{TM}}$ model. $^{2}$

\footnotetext{
\#\# The CBEAM element is a spatial 2-node beam element with axial, bending, and torsional capabilities and is supported within MSC.Nastran ${ }^{\mathrm{TM}}$ SOL106 for nonlinear large-deflection analysis. Its material and cross-sectional properties are defined using a PBEAM property record. Crosssectional properties may vary linearly from one end of the beam to the other along the local longitudinal axis of the beam element.

$\$ \S$ The CBAR element is a spatial 2-node beam element with axial, bending, and torsional capabilities. Its material and cross-sectional properties are defined using a PBAR property record. Cross-sectional properties are constant along the beam axis.

${ }^{* * * * *}$ The RBAR element is a 2-node rigid bar element with six degrees of freedom at each end. It functions as a multi-point constraint and is not supported for nonlinear analysis.

${ }^{+t^{+}}$The CGAP element is a uniaxial 2-node element that defines an initial gap with an axial stiffness once the gap is closed. Properties are defined using a PGAP record. The CGAP elements are not supported for nonlinear large deflection analysis.

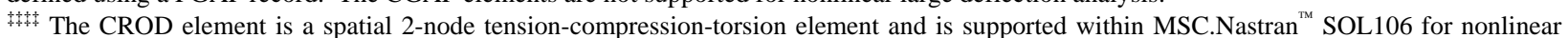
large-deflection analysis. Its material and cross-sectional properties are defined using a PROD property record.
} 
In summary, three analysis models are developed and evaluated. The first model is the ANSYS ${ }^{\circledR}$ model as extracted from the ATK ANSYS ${ }^{\circledR}$ model of the 4-bay configuration. The second model is the original Nastran ${ }^{\mathrm{TM}}$ model translated from ANSYS ${ }^{\circledR}$ model. The third model is the modified Nastran ${ }^{\mathrm{TM}}$ model with modeling features fully supported by MSC.Nastran ${ }^{\mathrm{TM}}$ SOL106. Predictions for a single straight longeron loaded in axial compression are presented next.

\section{Model Comparisons}

In the building-block approach, several analysis cases, as identified in Table 1, are considered and evaluated using a single straight longeron to determine any beam modeling differences between the two analysis tools. Eight nodes on the longeron ends are identified in Fig. 7 for the single-longeron study: five nodes at the corner end (i.e., nodes labeled C1, C2, C3, C4, and C5) and three nodes at the elbow end (i.e., nodes labeled E1, E2, E3). For each analysis case defined in Table 1, one of the elbow end nodes is restrained from any longitudinal (axial) motion, while one of the corner end nodes has an applied end displacement. Boundary conditions at the elbow end node for all cases are always the same (i.e., global DOFs T1, T2, T3, R1, and R3 are restrained. Similarly, boundary conditions at the corner end node are the same for all cases (i.e., global DOFs T1 and T2 are restrained, guided displacement), and the T3 DOF represents an applied end shortening. For the single longeron, the longeron end-toend condition includes the model from elbow node E1 to corner node C1, while the longeron pin-to-pin condition includes the model from elbow node E2 to corner node C2, see Fig. 7.

Case A defines a set of boundary conditions at nodes C5 and E3 and modeling assumptions for which the three models give identical solutions. Here, the load-displacement response is essentially a uniaxial stiffness check, since no geometric imperfection or eccentricity is included to trigger a nonlinear response. As a result, all three models predict the same peak axial reaction force of $4508 \mathrm{lb}$ for the imposed 0.03-inch applied end shortening.

Case B moves the corner end node to location C4, which includes the single non-colinear element along the longeron axis between nodes C4 and E3. Due to the slight eccentricity, a nonlinear response is generated with all three models predicting nearly the same axial reaction force for the same applied end displacement. These results indicate that, while the nonlinear response is mild, the models predict comparable peak axial force of $\sim 1680 \mathrm{lb}$.

Case C moves the corner end node to location C3, which includes the single non-colinear element and the notched corner end, and the longeron model now extends from corner end node C3 to elbow end node E3. Here, a five percent difference in the peak axial reaction force is noted for the original Nastran ${ }^{\mathrm{TM}}$ model, while the modified Nastran $^{\mathrm{TM}}$ model prediction compares well to the ANSYS ${ }^{\circledR}$ model prediction. The modeling difference for the modified Nastran $^{\mathrm{TM}}$ model in this case is due to replacing the RBAR elements in the original Nastran ${ }^{\mathrm{TM}}$ model with very stiff CBEAM elements for the notch offsets. Note that the influence of the eccentricity modeling is more evident in the modified Nastran ${ }^{\mathrm{TM}}$ model than the original Nastran ${ }^{\mathrm{TM}}$ model since not all modeling features are fully supported for large deflection analysis.

Case D moves the corner end node to location C2, which includes the single non-colinear element, the notched corner end, the pseudo clevis, and the pin at the corner end. The longeron model now extends from corner end node $\mathrm{C} 2$ at the pin to elbow end node E3 but does not include the clevis. The torsional stiffness of the pin is set to a very small value (i.e., $10^{-6}$ ) to simulate a free pin condition. In this case, the three models are essentially unchanged from the Case $\mathrm{C}$ results. However, additional eccentricity is introduced into the models by the location of node C2 along the pin at the corner end. In addition, since the pin is essentially 'free' to rotate about its axis, the response is expected to exhibit larger deflections. These effects are represented by the ANSYS ${ }^{\circledR}$ and modified Nastran ${ }^{\mathrm{TM}}$ models, while the original Nastran ${ }^{\mathrm{TM}}$ model appears to be limited by the use of modeling features not supported within SOL106.

Case E models the longeron from pin-to-pin (i.e., from node C2 to node E2), including the clevis and pin at the elbow end. The torsional stiffness of both pins is set to a very small value (i.e., $10^{-6}$ ) to simulate a free pin condition. The modified Nastran ${ }^{\mathrm{TM}}$ model and the ANSYS ${ }^{\circledR}$ model predict nearly the same peak axial reaction force; however, the original Nastran ${ }^{\mathrm{TM}}$ model predicts a peak axial reaction force similar to Case D that is 22 percent higher than the ANSYS ${ }^{\circledR}$ model predicts. Again, the original Nastran ${ }^{\mathrm{TM}}$ model appears to limited by the modeling features not being supported for large deflections.

Case F, the final case, models the longeron from end-to-end (i.e., node C1 to node E1). In this case, a compression dead band of 0.0004-inch is assumed. Again, the modified Nastran ${ }^{\mathrm{TM}}$ model and the ANSYS ${ }^{\circledR}$ model predict nearly the same peak axial reaction force of $\sim 1306 \mathrm{lb}$ for an applied end displacement of 0.03 inches. However, the original Nastran $^{\mathrm{TM}}$ model predicts a peak axial reaction force that is 22 percent higher than the ANSYS $^{\circledR}$ model predicts for this case, and essentially the same peak axial force as predicted for Cases C, D, and E. 
Again, modeling features in the original Nastran ${ }^{\mathrm{TM}}$ model not supported for large deflection analysis in SOL106 appear to influence the results significantly.

A summary of these findings is given in Table 1 where the results obtained using the original (or the initial astranslated) Nastran ${ }^{\mathrm{TM}}$ model, the modified Nastran ${ }^{\mathrm{TM}}$ model, and the ANSYS ${ }^{\circledR}$ model are presented. For each case, the modifications to the original Nastran ${ }^{\mathrm{TM}}$ model are identified. The final single-longeron case for comparison (Case F) involves the entire longeron, the fittings, pins, and the load-path modeling through the end joints. The nonlinear response predictions for the ANSYS ${ }^{\circledR}$ model and the modified Nastran ${ }^{\mathrm{TM}}$ model are shown in Fig. 9. The influence of the joint fitting dead band on the load-displacement response appears to be limited to the initial loading of the longeron and results in a shift in the load-displacement response. However, the rod area parameter in the joint fitting load path model has a marked influence on the initial slope of the load-displacement curve (i.e., larger area, higher stiffness) but minimal influence on the peak reaction force. Again, good correlation between the two analysis tools was achieved for not only the peak axial reaction load but also for the initial axial stiffness of the model as evident in Fig. 9. From these results, the ANSYS ${ }^{\circledR}$ model and the modified Nastran ${ }^{\mathrm{TM}}$ model of the single straight longeron are verified.

In all of the previous cases, the finite element mesh along the axis of the longeron has nineteen 2-node beam elements between corner node C5 and elbow node E3. Using the Case F modified Nastran ${ }^{\mathrm{TM}}$ model, a mesh convergence study is performed that varies the number of elements in the middle region of the longeron as shown in Fig. 10. For each mesh, the peak axial reaction force for a 0.2 -inch end shortening is normalized by the peak value obtained using fifty elements in the middle region of the longeron. For this end shortening value, the peak axial reaction force is constant for a given mesh. Using nineteen elements, results in less than 0.2 percent change in peak axial force, and ten elements results in less than a one percent change. Based on these results, fewer beam elements are needed; however, the finer mesh is maintained in order to recover displacement and strain values associated with instrumentation used in the single-longeron testing.

Table 1. Comparison of maximum axial reaction force for a specified 0.03-inch end shortening for different cases.

\begin{tabular}{|c|c|c|c|c|c|}
\hline Case & Model & $\begin{array}{l}\text { Elbow End } \\
\text { Node }\end{array}$ & $\begin{array}{l}\text { Corner } \\
\text { End Node }\end{array}$ & $\begin{array}{l}\text { Elbow } \\
\text { Reaction } \\
\text { Force, lb }\end{array}$ & Comment \\
\hline \multirow{3}{*}{ A } & ANSYS $^{\circledR}$ & \multirow{3}{*}{ E3 } & \multirow{3}{*}{ C5 } & 4508 & \multirow{3}{*}{ Straight longeron, no eccentricities } \\
\hline & Original Nastran $^{\mathrm{TM}}$ & & & 4508 & \\
\hline & Modified Nastran $^{\mathrm{TM}}$ & & & 4508 & \\
\hline \multirow{3}{*}{ B } & ANSYS $^{\circledR}$ & \multirow{3}{*}{ E3 } & \multirow{3}{*}{$\mathrm{C} 4$} & 1685 & \multirow{3}{*}{$\begin{array}{l}\text { Corner boundary node changed to } \\
\text { include slight eccentricty in last element } \\
\text { before the notch }\end{array}$} \\
\hline & Original Nastran $^{\mathrm{TM}}$ & & & 1680 & \\
\hline & Modified Nastran $^{\mathrm{TM}}$ & & & 1678 & \\
\hline \multirow{3}{*}{$\mathrm{C}$} & ANSYS $^{\circledR}$ & \multirow{3}{*}{ E3 } & \multirow{3}{*}{ C3 } & 1514 & \multirow{3}{*}{$\begin{array}{llll}\text { Corner } & \text { boundary } & \text { node } & \text { changed to } \\
\text { include notch at } & \text { corner } & \text { end (offset } \\
\text { beams) } & & & \end{array}$} \\
\hline & Original Nastran $^{\mathrm{TM}}$ & & & 1590 & \\
\hline & Modified Nastran $^{\mathrm{TM}}$ & & & 1508 & \\
\hline \multirow{3}{*}{ D } & ANSYS $^{\circledR}$ & \multirow{3}{*}{ E3 } & \multirow{3}{*}{$\mathrm{C} 2$} & 1510 & \multirow{3}{*}{$\begin{array}{l}\text { Corner boundary node changed to } \\
\text { include notch and 'pseudo-clevis' for } \\
\text { corner fitting pin }\end{array}$} \\
\hline & Original Nastran $^{\mathrm{TM}}$ & & & 1590 & \\
\hline & Modified Nastran $^{\mathrm{TM}}$ & & & 1508 & \\
\hline \multirow{3}{*}{$\mathrm{E}$} & ANSYS $^{\circledR}$ & \multirow{3}{*}{ E2 } & \multirow{3}{*}{$\mathrm{C} 2$} & 1307 & \multirow{3}{*}{$\begin{array}{l}\text { Pin-to-pin model; includes the notched } \\
\text { end and the clevis end pins }\end{array}$} \\
\hline & Original Nastran $^{\mathrm{TM}}$ & & & 1597 & \\
\hline & Modified Nastran $^{\text {TM }}$ & & & 1305 & \\
\hline \multirow{3}{*}{ F } & ANSYS $^{\circledR}$ & \multirow{3}{*}{ E1 } & \multirow{3}{*}{ C1 } & 1306 & \multirow{3}{*}{$\begin{array}{l}\text { End-to-end model; fitting dead bands } \\
\text { included }\end{array}$} \\
\hline & Original Nastran $^{\mathrm{TM}}$ & & & 1594 & \\
\hline & Modified Nastran $^{\mathrm{TM}}$ & & & 1314 & \\
\hline
\end{tabular}

9

American Institute of Aeronautics and Astronautics 


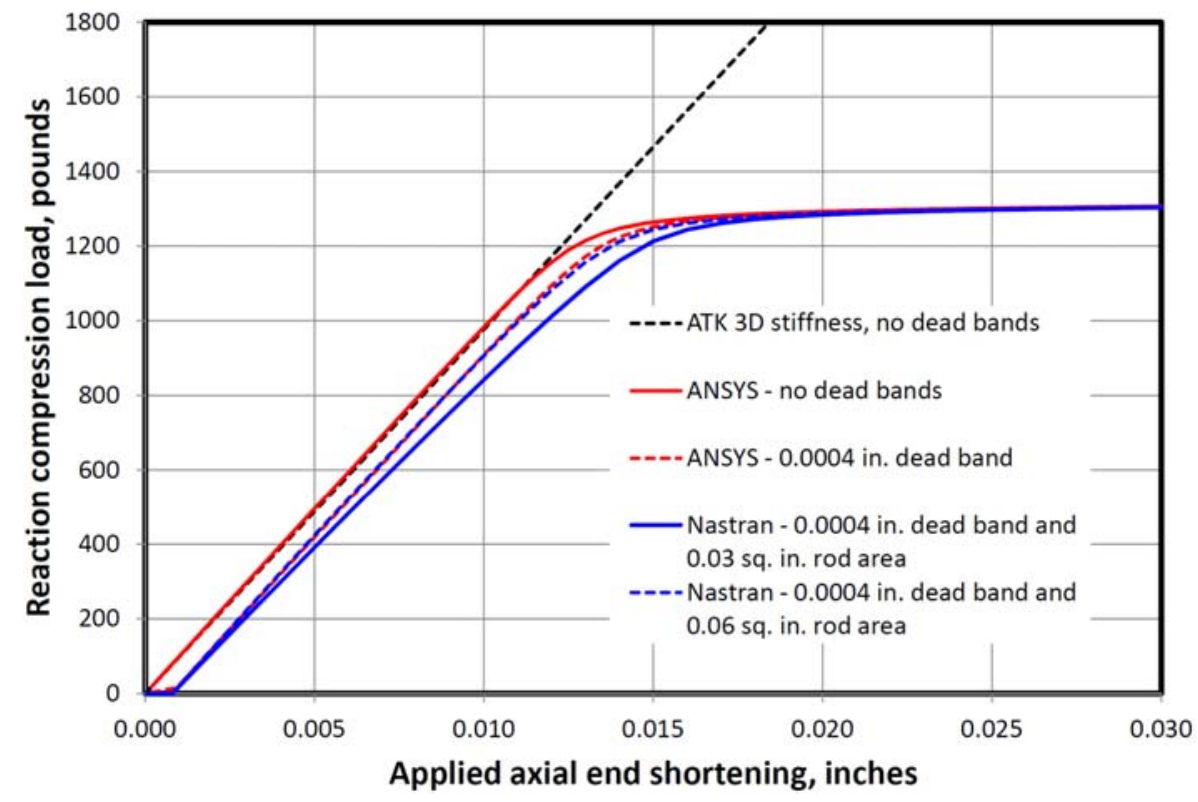

Figure 9. Nonlinear response predictions for Case F.

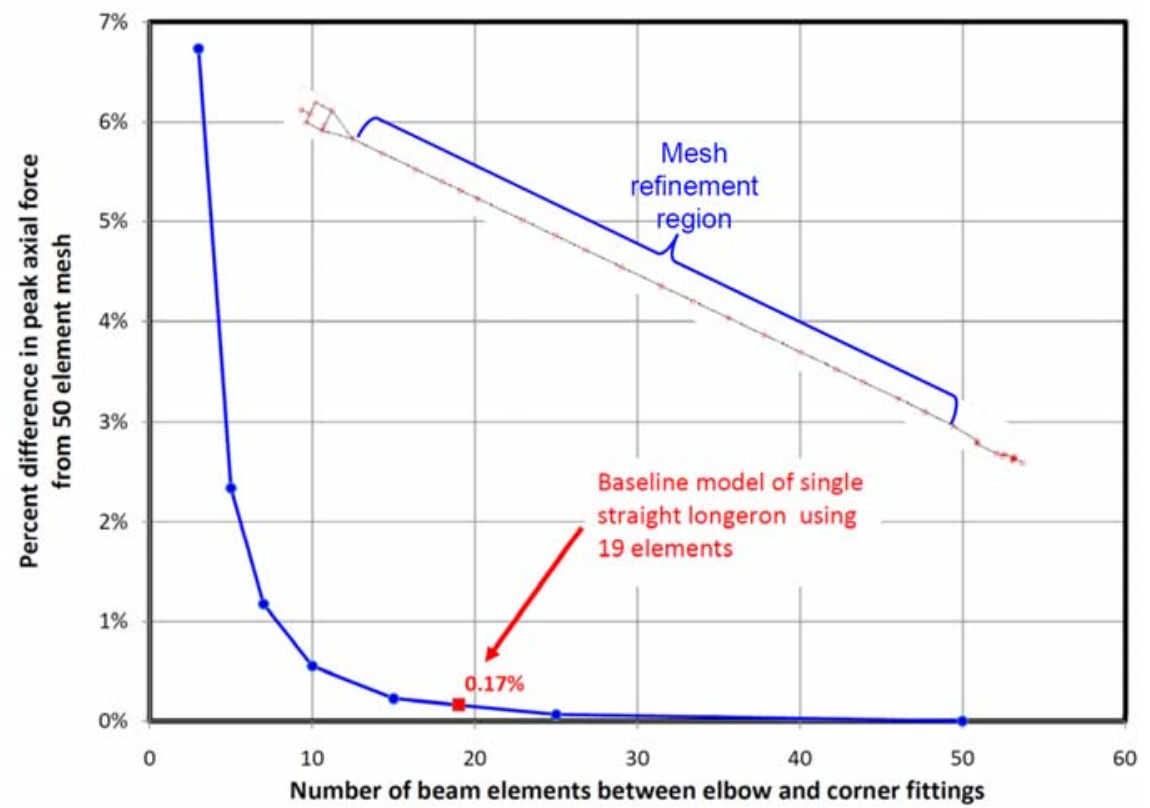

Figure 10. Effect of mesh refinement on predicted peak axial reaction force for 0.2 inches of applied end shortening using the modified Nastran ${ }^{\mathrm{TM}}$ model. 


\section{Test-Analysis Correlation}

Once the MSC Nastran ${ }^{\mathrm{TM}}$ model of the single straight longeron predicted nearly the same responses as the ANSYS $^{\circledR}$ model, attention is directed towards comparing the MSC Nastran ${ }^{\mathrm{TM}}$ results to the single longeron test data generated at NASA Langley, see Ref. 13. Individual longerons are loaded axially (in tension and compression) to determine their structural response and provide calibration and validation data for the analysis models. A series of load cycling tests were performed under displacement control. The tension loading is to approximately 1000 pounds, and the compression loading is just beyond buckling but within the elastic limit. Both displacement and strain data are recorded from these tests.

Table 2. Parameter definitions for the Nastran ${ }^{\mathrm{TM}}$ model.

\begin{tabular}{|l|c|c|}
\hline \multicolumn{1}{|c|}{ Parameter } & Units & $\begin{array}{c}\text { Values for the } \\
\text { Reconciled } \\
\text { Nastran }\end{array}{ }^{\mathrm{TM}}$ Model \\
Nongeron elastic modulus & $\mathrm{Msi}$ & 10.51 \\
\hline Lond band tensile initial strain & $\mu \mathrm{in} / \mathrm{in}$ & 1496 \\
\hline Dead & $\mu$ in/in & -2204 \\
\hline Dead band compressive initial strain & $\mathrm{in}^{2}$ & .0231 \\
\hline Load introduction rod tensile area & $\mathrm{in}^{2}$ & .060 \\
\hline Load introduction rod compressive area & $\mathrm{in}^{4}$ & $2.17 \mathrm{E}-4$ \\
\hline Corner load introduction beam $\mathrm{I}_{1}$ & $\mathrm{in}^{4}$ & $6.08 \mathrm{E}-4$ \\
\hline Corner load introduction beam $\mathrm{I}_{2}$ & $\mathrm{in}^{4}$ & $3.13 \mathrm{E}-3$ \\
\hline Elbow load introduction beam $\mathrm{I}_{1}$ & $\mathrm{in}^{4}$ & $5.26 \mathrm{E}-4$ \\
\hline Elbow load introduction beam $\mathrm{I}_{2}$ & & \\
\hline
\end{tabular}

Parameters associated with modeling assumptions in the modified Nastran ${ }^{\mathrm{TM}}$ model are identified and their influence on the nonlinear response prediction including correlation with strain gage data posed a new challenge even though good correlation between the ANSYS $^{\circledR}$ and modified Nastran ${ }^{\mathrm{TM}}$ models of the single straight longeron had been demonstrated. Different sets of modeling parameters were assessed that included longeron elastic modulus, pin or axle torsional stiffness, tension dead band initial strain and stiffness, compression dead band initial strain and stiffness, joint load path rod element areas for tension and compression, joint load path beam element section properties, location along pin of joint load path attachment, and modulus used to define 'very stiff' elements used in notch and pseudo-clevis offset modeling. The procedure used to assess these parameters, their bounds, and their distributions are described in Ref. 13.

After numerous studies, a smaller set of model parameters was defined as listed in Table 2. The values for each parameter in Table 2 attempts to minimize the errors between the average test results and the analysis results simultaneously for metrics defined on the tension and compression slopes of the load vs displacement curve, axial strain curve, and the two bending strains. ${ }^{13}$ These values for the parameters define the reconciled Nastran ${ }^{\mathrm{TM}}$ model for the single straight longeron. Based on these parameter values, the predicted single straight longeron response is shown in Figs. 11 through 14 along with the average test results along with their minimum and maximum trends for the entire loading range. Note that the 31-bending plane is bending in a plane that contains the pin axis of rotation, whereas the 23-bending plane is orthogonal to the pin axis (see Fig. 7).

These results indicate excellent correlation between the test and analysis up to the buckling value, which is denoted by the filled yellow circle in Figs. 11 through 14. Results beyond this point can be influenced by the frictional forces in the mechanical joints. Initially, the response appears to correspond to a 'locked' pin condition; however, as the critical load is approached, the frictional forces in the joints may be overcome and slippage could occur similar to a 'free' pin condition. Such combined nonlinear behavior cannot currently be simulated within a single analysis model unless a nonlinear torsional spring capability is available or detailed three-dimensional modeling is performed. Nonetheless, these results for the reconciled Nastran ${ }^{\mathrm{TM}}$ model indicate that excellent axial and bending strain correlations can be achieved for both the tension and compression loading cycles up to buckling. Local modeling of the mechanical joints is addressed further in the single-bay models. 


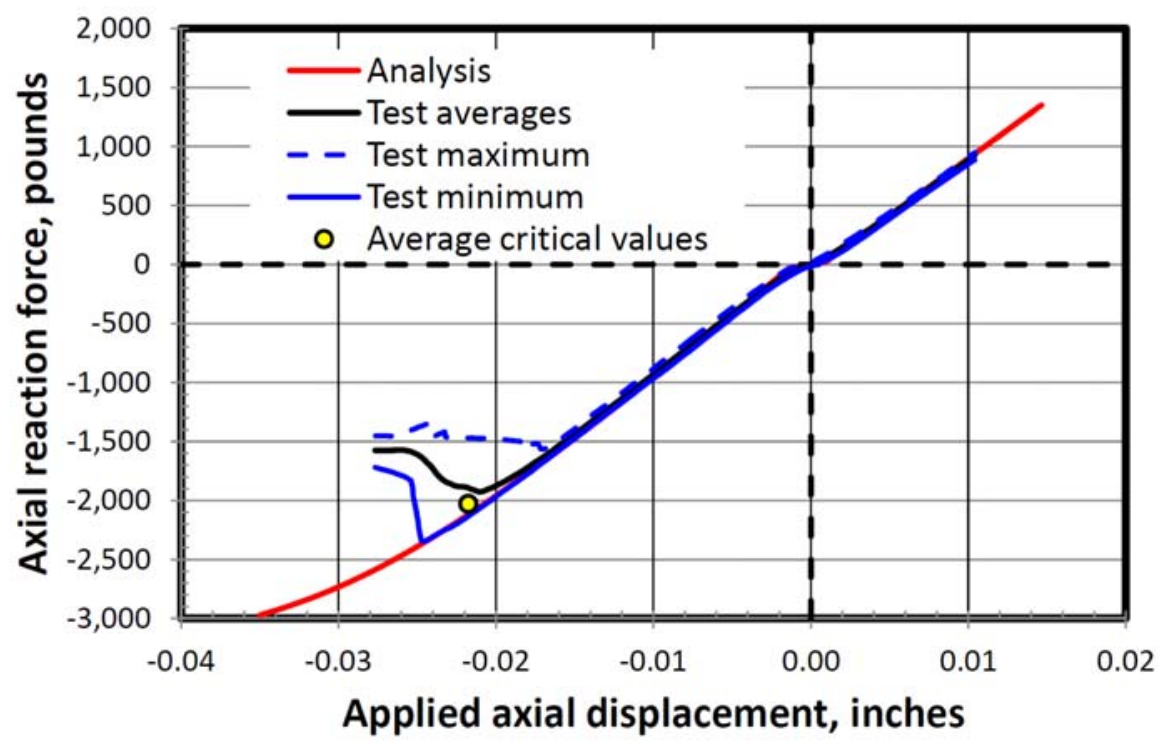

Figure 11. Comparison of load vs. end displacement results for the reconciled Nastran $^{\mathrm{TM}}$ model to average test response.

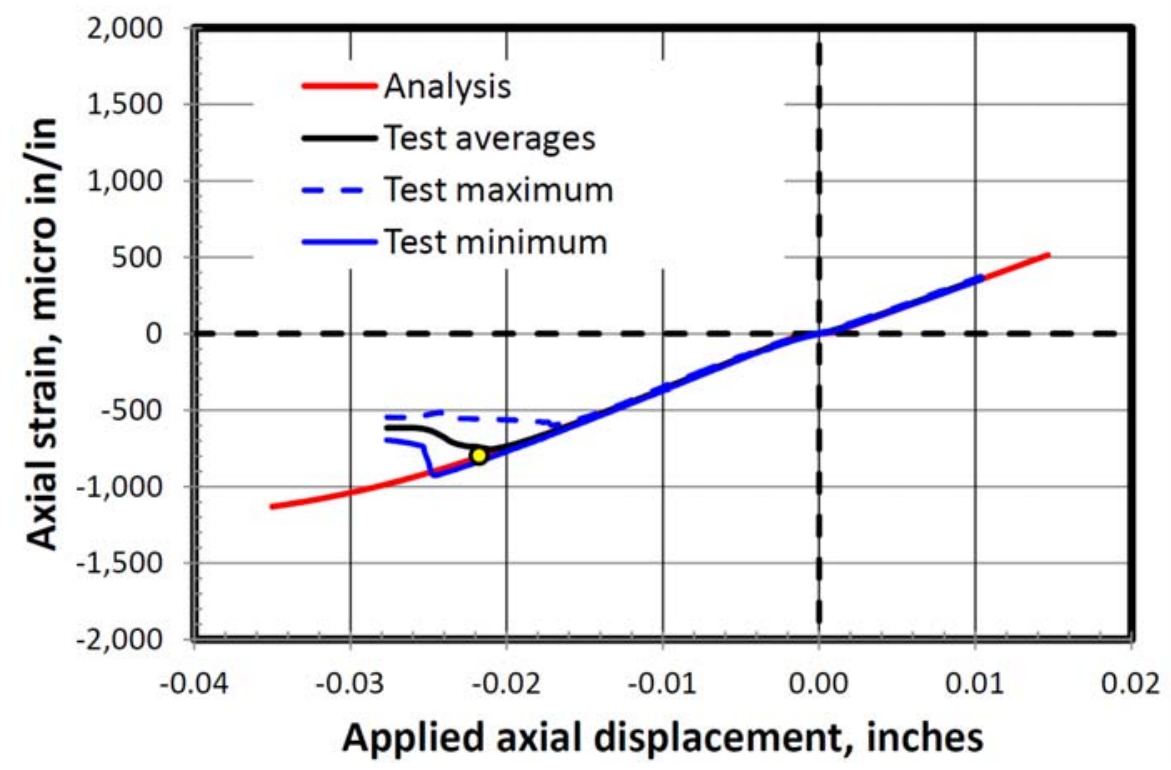

Figure 12. Comparison of axial strain vs. end displacement results for the reconciled Nastran ${ }^{\mathrm{TM}}$ model to average test response.

12

American Institute of Aeronautics and Astronautics 


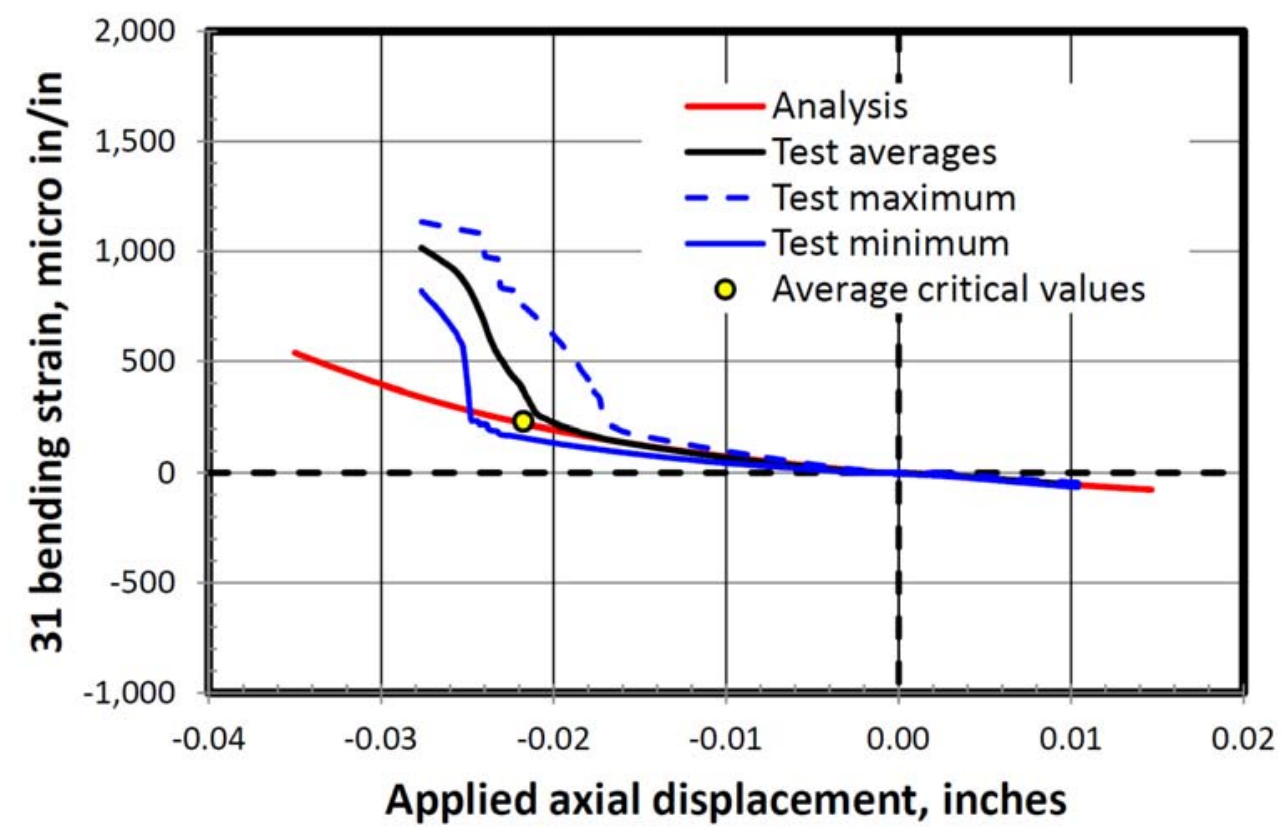

Figure 13. Comparison of transverse 31 bending strain vs. end displacement results for the reconciled Nastran ${ }^{\mathrm{TM}}$ model to average test response.

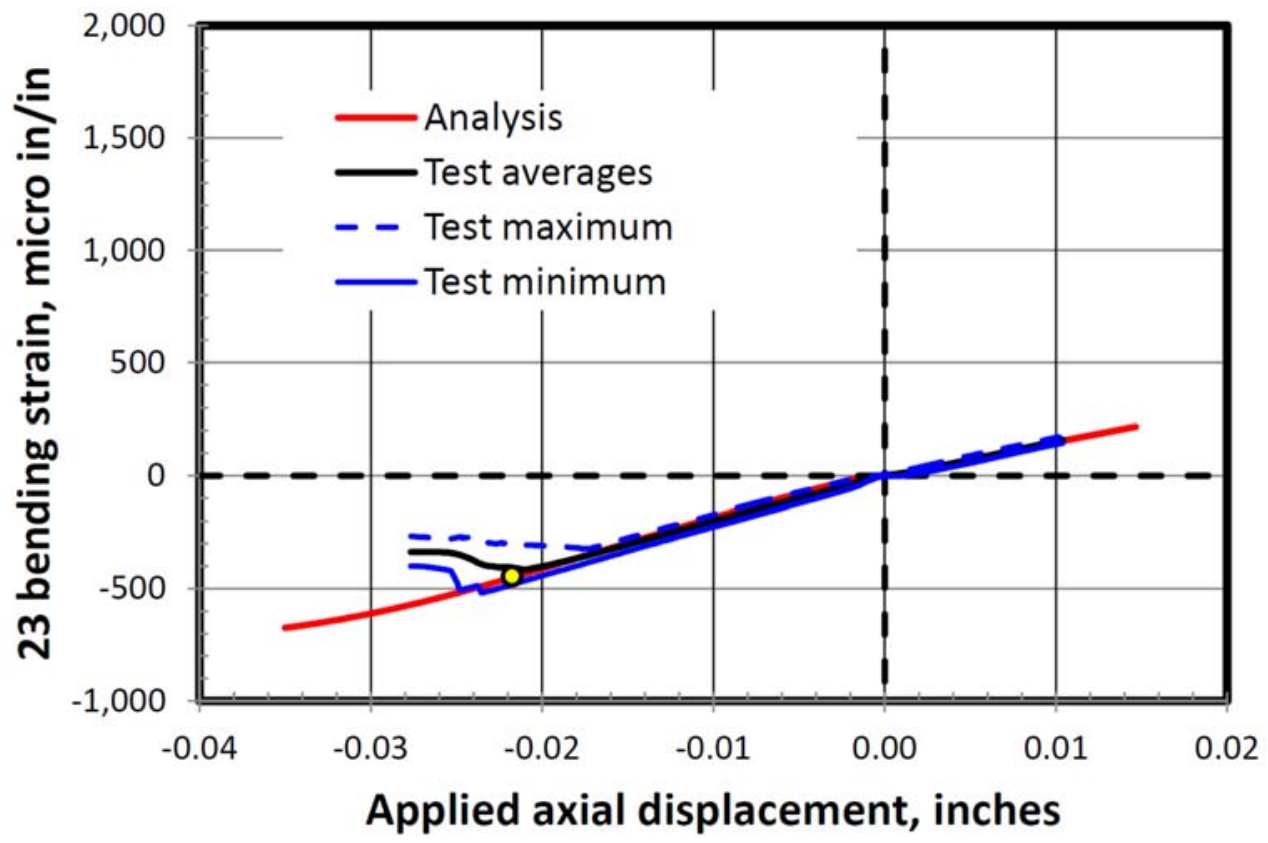

Figure 14. Comparison of lateral 23 bending strain vs. end displacement results for the reconciled Nastran $^{\mathrm{TM}}$ model to average test response.

13

American Institute of Aeronautics and Astronautics 


\section{Single-Bay Response}

After the thermal testing at JPL, a single bay was extracted from the 4-bay hardware configuration for subsequent axial load testing at NASA Langley. The single-bay test configuration is shown in Fig. 15 , where a single longeron pair, shown in the foreground, is loaded axially, while the other three longeron pairs are free. An off-load pulley system is included to counterbalance the weight of the single bay - not included in the model. Displacements were recorded using LVDTs $^{\S \S \S \S}$ as well as digital image correlation images. Note that the xial strain gages were located 10 inches from the elbow end, and bending strain gages were located 16 inches from the elbow end as shown in Fig. 5.

The axial load is introduced using displacement control, and the average load versus end displacement response is shown in Fig. 16 by the solid black curve and the minimum and maximum test bounds are shown as blue curves. The response indicates the tension and compression load cycle with 'buckling' of the loaded longeron occuring at about 1720 pounds from a 'locked' pin condition. Micro-slipping within the mechanical joints apparently results in a slightly lower load from which the 'S-shaped' buckle develops (see Fig. 17a) until the loaded longeron pair folds (see Fig. 17b). Note that Strut A in Fig. 17a is more buckled and exhibits more out-ofplane deflection than Strut B, which is less buckled.The average

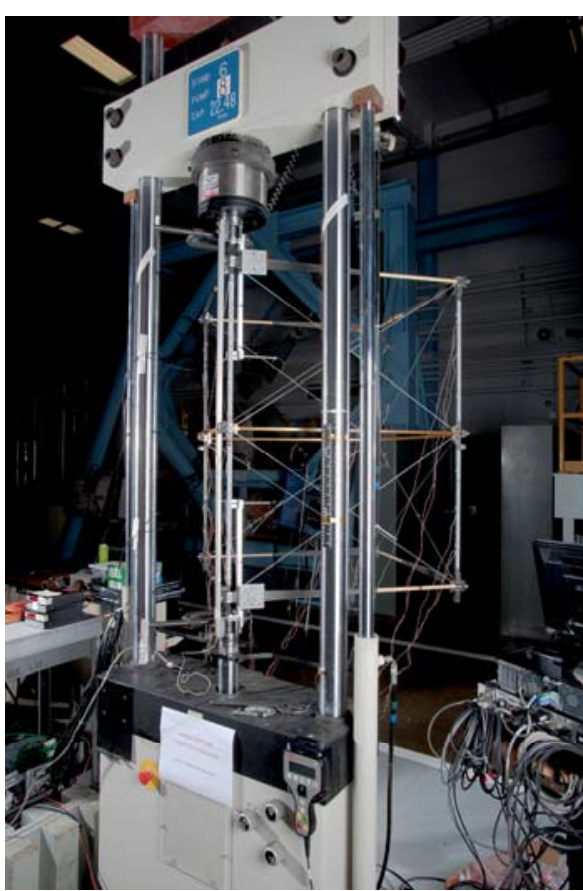

Figure 15. Single-bay test configuration. point for the mechanical folding of the bay is indicated by the filled yellow symbol in Fig. 16 (i.e., at 1442 pounds of compression and -0.154 inches of end displacement).

Axial and bending strains are measured during the test, and these strains can be used to determine the surface strains. The primary surface strains, those in the plane of the buckle (31 plane; the plane containing the pin axis of rotation), are shown in Fig. 17 and indicate that the compressive surface strains exceed the elastic strain limit of approximately $3000 \mu \mathrm{in} / \mathrm{in}$. These results indicate that for the straight longeron pairs an elasticplastic analytsis capability is needed in order to simulate the response after initial buckling.

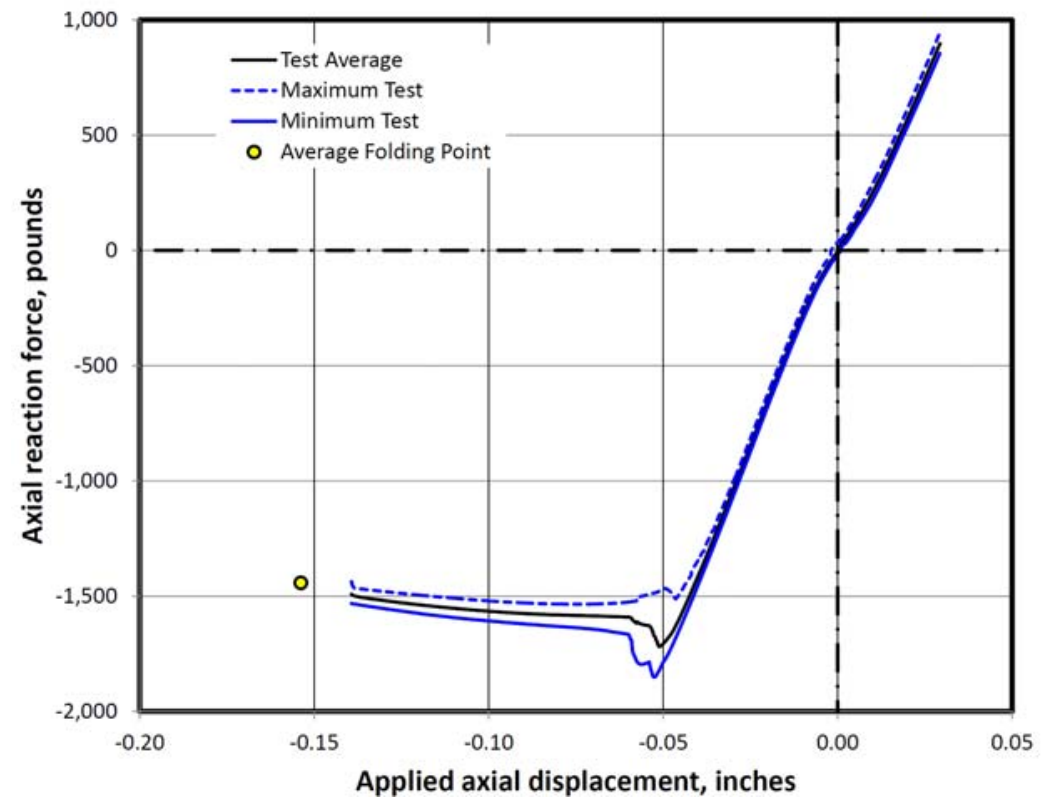

Figure 16. Straight-longeron, single-bay load versus end displacement test results: average and bounds.

\footnotetext{
${ }^{\S \S \S}$ Linear Variable Differential Transformer.
} 


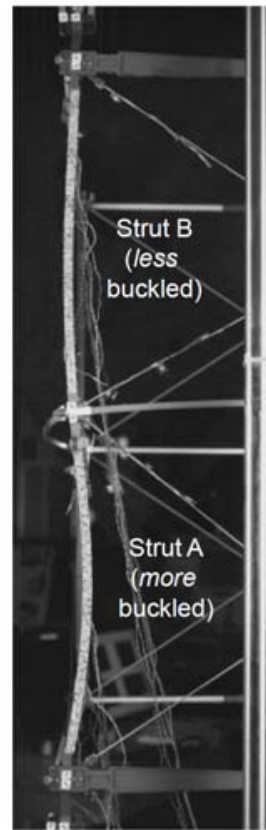

(a) After buckling.

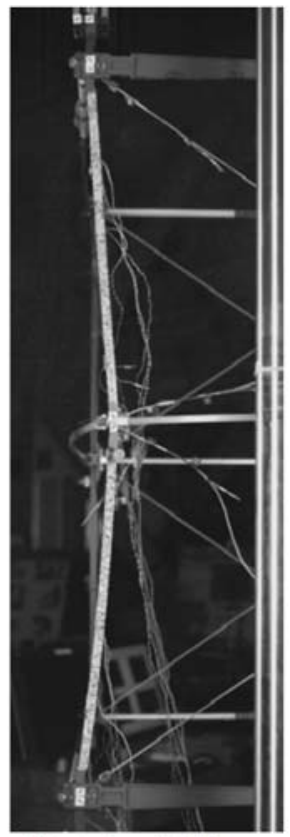

(b) After folding.

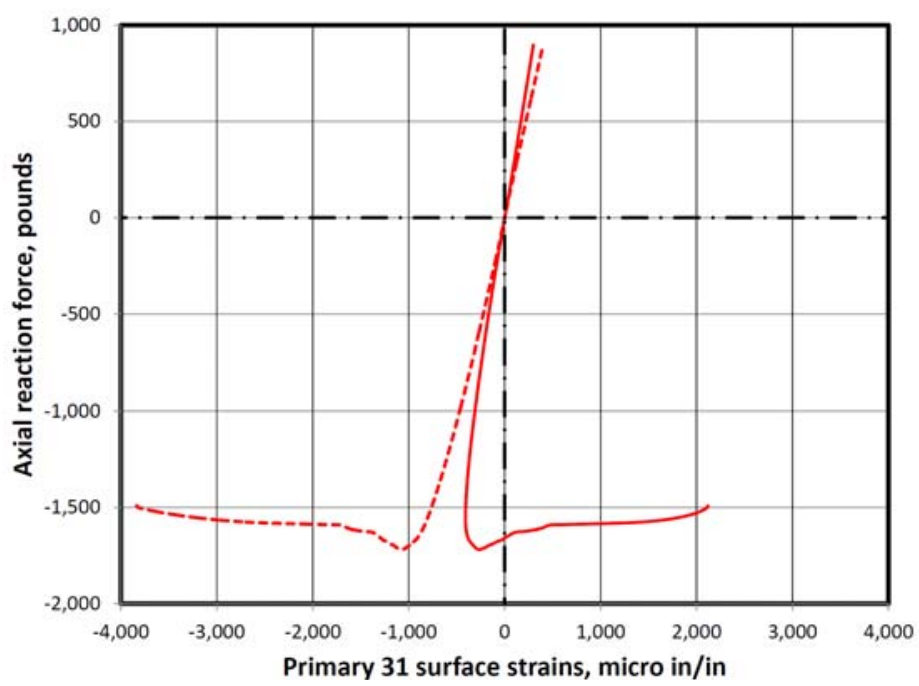

Figure 18. Test-averaged surface strains for loaded longeron

Figure 17. Photographs of typical loaded longeron: after buckling and after folding.

\section{Single-Bay Model Translation}

The model translation approach for the single bay configuration was more involved at the beginning of the simulation due to several factors. First, the original modeling of the rigid battens did not include the taper in the Cchannel segment (see Fig. A4 in the appendix). The finite element model for Nastran ${ }^{\mathrm{TM}}$ is modified to include this feature. Second, the rigid batten connections at the corner joints in the original model are internal to the mast rather than external. Again, the Nastran ${ }^{\mathrm{TM}}$ model was modified to reflect this geometric feature. Third, the flex battens in the original model are modeled using a beam element wherein the axial stiffness is defined based on its nominal preload and treated as a constant. In the Nastran ${ }^{\mathrm{TM}}$ model, the flex battens are modeled using a single rod element with a nonlinear stress-strain curve to simulate its postbuckling stiffness and a beam element to represent any bending and torsional response. Additional details are given in the appendix. Fourth, the initial assembly of the single bay results in initial preloads in the major structural elements. Measurements taken on a single-bay configuration sitting on four ends give, on average: 55 pounds of compression in the flex battens, 33 pounds of tension in the diagonal cables, 36 pounds of compression in the longerons, and 27 pounds compression in the rigid battens. Since assembly is not simulated, a non-physical temperature differential is specified for the flex battens and diagonal cables in order to generate the preload in each element of the single bay. The initial temperature for the flex batten rod elements is taken as $-5000^{\circ} \mathrm{C}$, and the initial temperature of the diagonal cable elements is varied. Again, these initial temperatures are specified to generate the member preload forces. All other elements are set to room temperature or $21^{\circ} \mathrm{C}$. The final temperature is then set to room temperature, and the resulting thermal strains generate the member preloads.

The influence of the initial temperature imposed on the diagonal cables on the preload in the other single-bay structural members is indicated in Fig. 19. The dashed lines represent the averaged measured values for the diagonal cables and derived values for the other members. When initial temperature of the diagonal cables is set to room temperature $\left(21^{\circ} \mathrm{C}\right)$, the preload forces are caused only by the temperature differential imposed on the flex battens. As the initial temperature of the diagonal cables increased, the predicted preload values also increase and can be adjusted to match the measured values. 


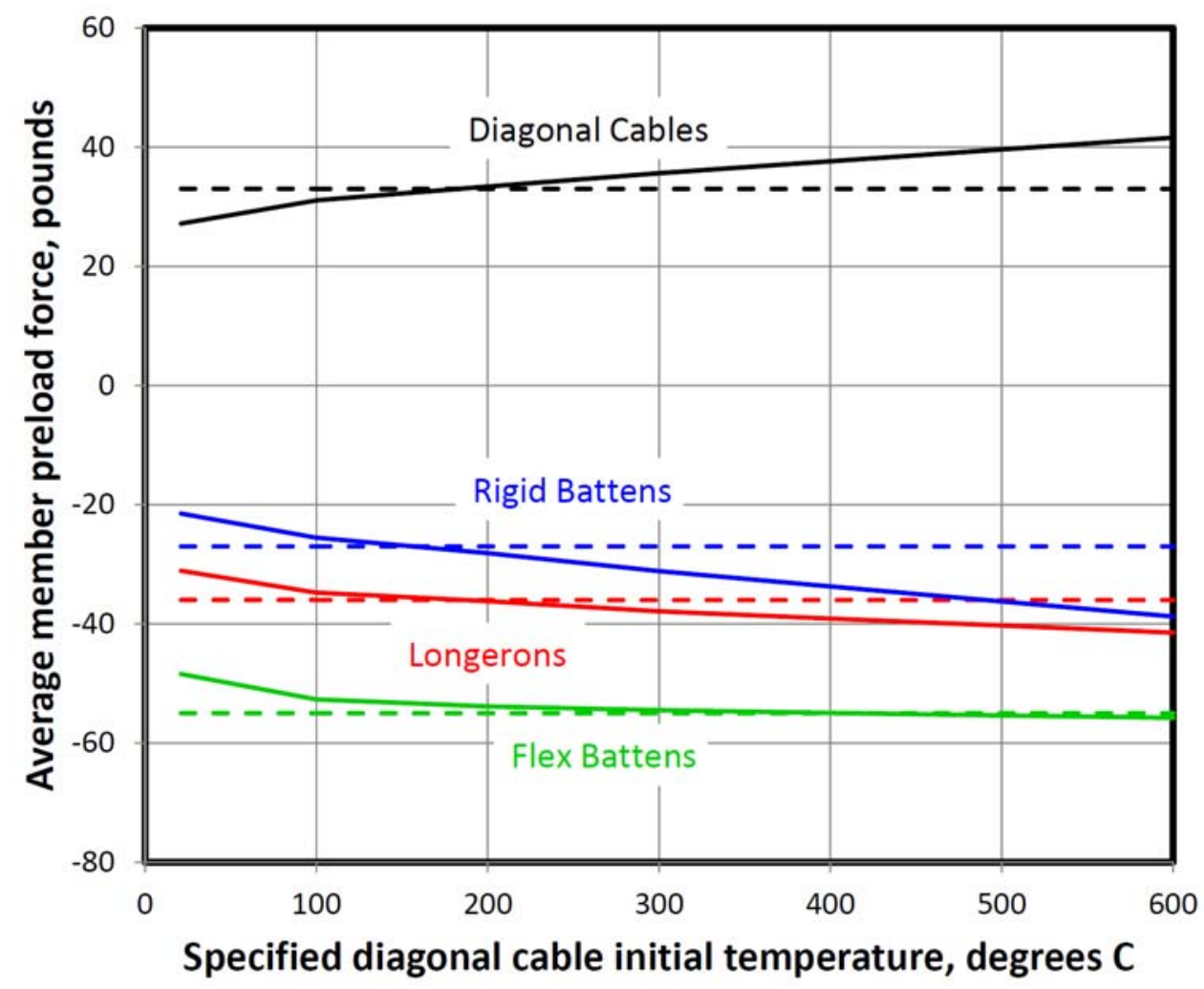

Figure 19. Influence of diagonal cable initial temperature on structural member preload forces.

\section{Single-Longeron Modeling Extended to a Single Bay}

As a final step, adjustments to the MSC.Nastran ${ }^{\mathrm{TM}}$ single-bay model are needed to incorporate the geometry related changes resulting for the calibration process ${ }^{13}$. Nodal locations of five nodes at the corner end (C1-C5) and three nodes at the elbow end (E1-E3) need to be updated based on the calibration results from the single longeron study. These nodal locations adjust the load introduction path on the pin and potential eccentricities associated with the joints. These updates had to be introduced at the sixteen joint locations of the single bay plus at the eight joints used as load introduction fittings. Once the geometry is updated, it is fixed for the single longeron simulations.

The next step is to implement the reconciled solution parameter set determined from the single longeron study (see Table 2) throughout the Nastran ${ }^{\mathrm{TM}}$ single-bay model. Strong couplings are exhibited among some of these parameters making tuning of the model to test data even more complicated for the single-bay case than for the single-longeron case. The load introduction modeling (i.e., overlaid beam and rod elements) is assumed to be the same for both the elbow and corner joints but with different definitions for tension and compression. The corner and elbow joint pins are also assumed to be the same at both locations and initially assumed to have a 'locked' pin condition (i.e., high value for the torsional constant J).

Predicted load versus end displacement results for four cases are shown in Fig. 20. For each case, the initial response for tension and compression loading including joint dead bands is consistently predicted. The first case shown by the short dashed curve in Fig. 20 uses the Table 2 parameter set with a diagonal cable initial temperature of $500^{\circ} \mathrm{C}$ and predicts a somewhat higher buckling load. Also, the buckling shape is in a plane opposite of that observed during testing and no folding is predicted.

The second case shown by the longer dash curve in Fig. 20 uses the values for the parameter set given in Table 2 with two exceptions. Here, the $\mathrm{I}_{2}$ value for corner load-introduction beam element and the $\mathrm{I}_{1}$ value for elbow loadintroduction beam element are reduced by a factor of ten compared to the values listed in Table 2; while the 
diagonal cable initial temperature is kept at $500^{\circ} \mathrm{C}$. This response shows a lower buckling load with the buckle shape being in the same plane as the test and a folding response at about -0.22 inches of end displacement.

The third case shown by the dotted curve in Fig. 20 uses the same parameter set as the second case except that the diagonal cable initial temperature is increased $600^{\circ} \mathrm{C}$ (slight increase in preload forces). This response coincides with the second case except that folding occurs earlier (-0.14 inches of end displacement).

The final case shown by the solid curve in Fig. 20 is identical to the third case except that the torsional stiffness of the corner and elbow joint pins is reduced to a near free condition (the value listed in Table 2 is divided by 100). This response is also similar to the previous two cases except for the slight drop in load when buckling occurred. After folding, the axial force in the model remains at about 500 pounds since the model contains stiffness in the joint and is not completely free. Deformed configurations with exaggerated displacements are shown in Fig. 21 to illustrate that the model does predict the 'S-shaped' buckling model in the correct plane and does predict folding. Given these results, attention is now given to test-analysis correlation using the parameter set and preloads defined from this fourth case.

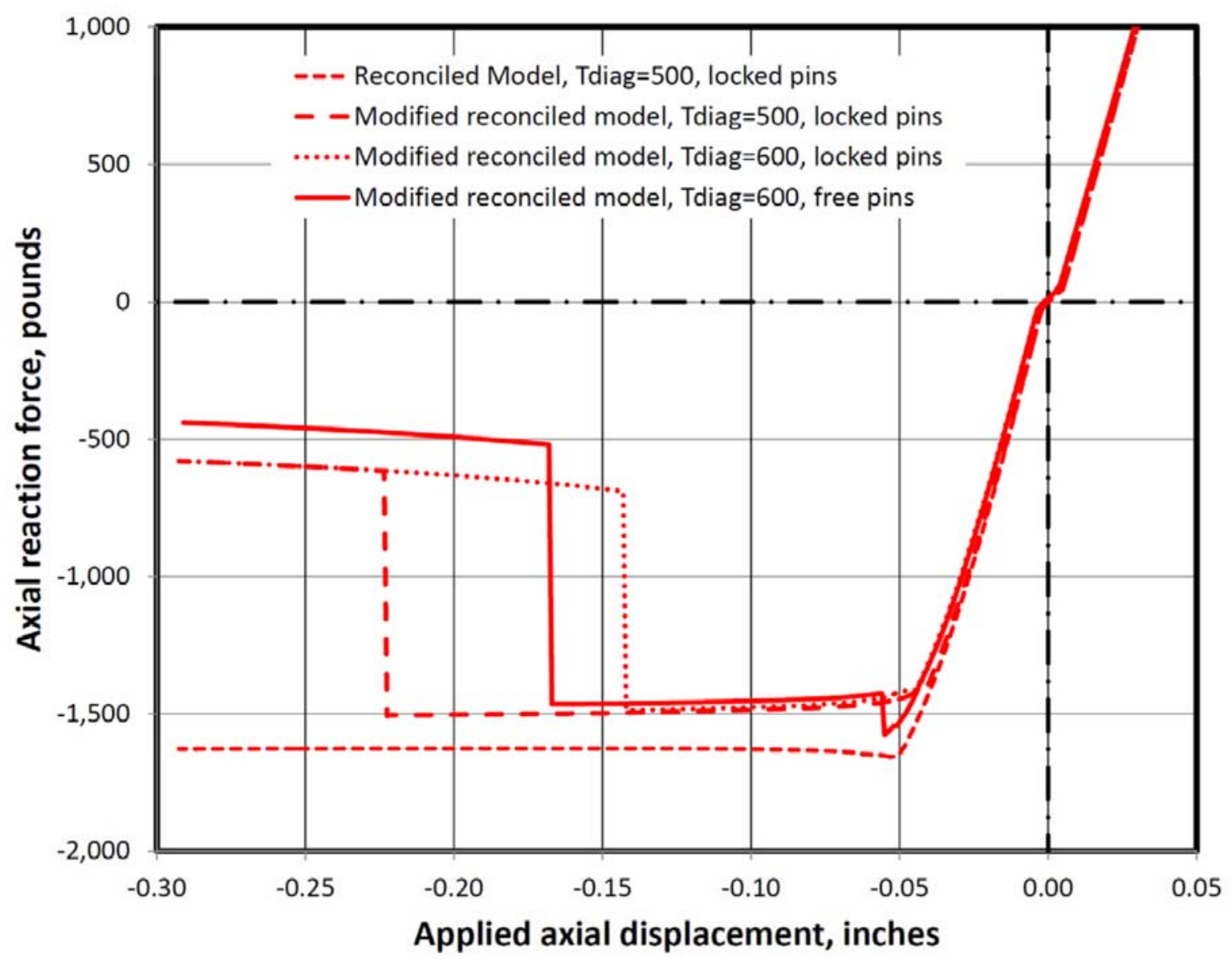

Figure 20. Comparison of analtyical predictions of the load versus end displacement for models based on the reconciled solution parameter set given in Table 2 . 


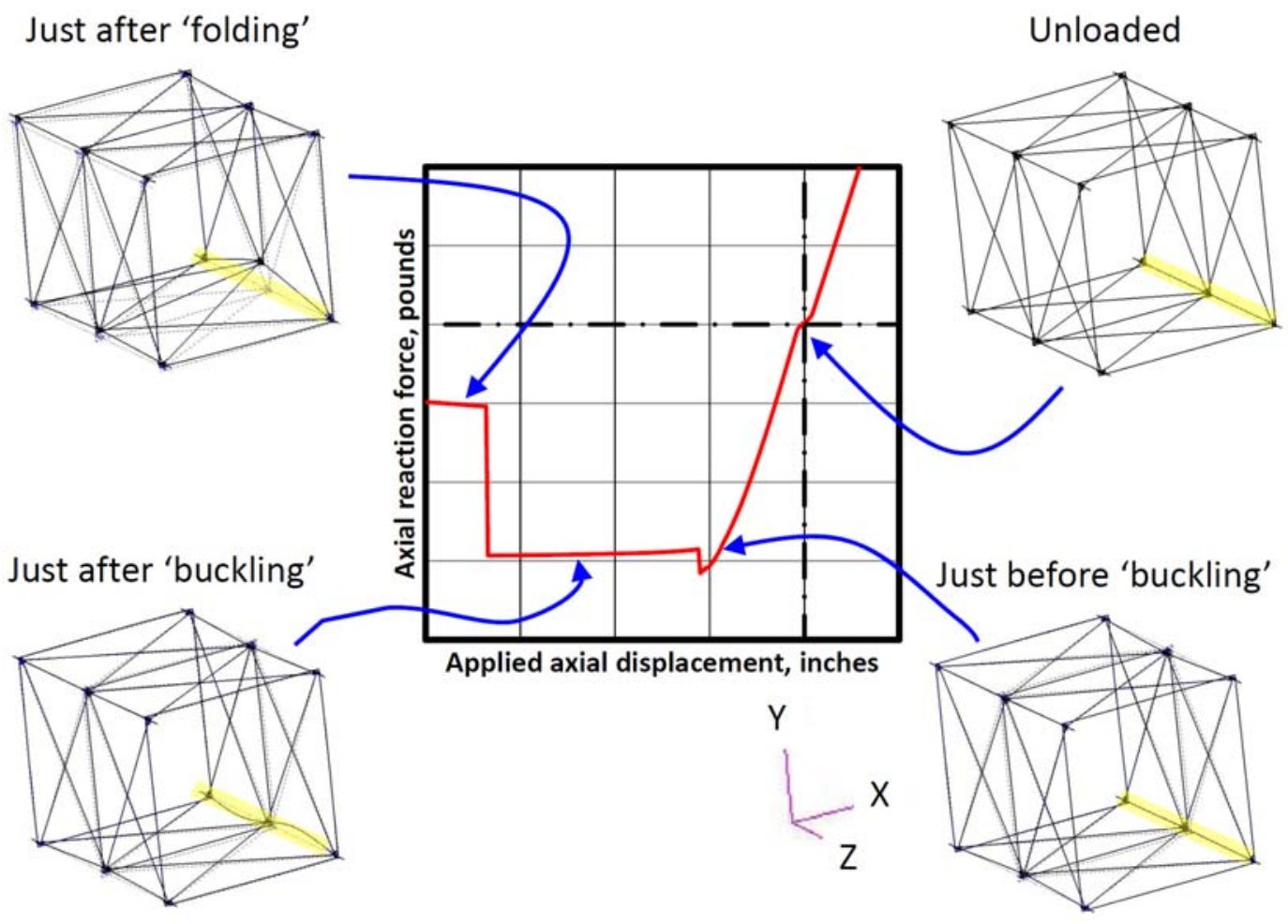

Figure 21. Deformed geometry shapes with exaggerated displacements illustrating undeformed shape, pre-buckling deformed shape, after buckling shape, and after folding shape. The loaded longeron is highlighted in yellow.

\section{Test-Analysis Correlation}

Comparisons of results obtained using the final case MSC Nastran ${ }^{\mathrm{TM}}$ model to average single-bay test data are performed to verify the single-bay modeling approach. Results for a tension-to-compression loading cycle including buckling and folding are shown in Figs. 22 through 26. In these figures, the average test response is shown as a black solid curve, and the minimum and maximum bounds are shown as blue curves. The MSC.Nastran ${ }^{\mathrm{TM}}$ predictions are shown as the red curves. The filled circular symbols on these figures represents the average folding point for the figure's parameters.

The load versus end displacement response is shown in Fig. 22. Prior to buckling, good correlation is evident; however, as the buckling load is approached, the analytical predictions fall outside the test bounds. The model does predict both buckling and folding at approximately the same end displacement values as recorded during the test.

The axial strain as a function of the end displacement is shown in Fig. 23 for the more buckled longeron (Strut A) and in Fig. 24 for the less buckled longeron (Strut B). The more buckled longeron exhibits higher axial strains than the less buckled longeron due to localized plasticity that develops after buckling causing the increase in axial strain as shown in Fig. 23. Note that the MSC.Nastran ${ }^{\mathrm{TM}}$ results, which are linear elastic, do not exhibit this increase and the two longerons behave in a very similar manner.

The primary bending strain (i.e., due to rotation about the pin axis) shown in Fig. 25 as a function of end displacement again illustrates that the MSC.Nastran ${ }^{\mathrm{TM}}$ model correlates well with the test data up to buckling. The solid red curve represents the more buckled longeron, while the red dashed curve represents the less buckled longeron. Note that the bending strains alone approach the elastic strain limit for this material.

Finally, the secondary bending strains (i.e., due to rotation normal to the pin axis) are predicted to be small and compressive and are consistent with those reported from the test as shown in Fig. 26. The solid red curve represents 
the more buckled longeron, while the red dashed curve represents the less buckled longeron. Prior to buckling, good correlation is evident. After buckling, these bending strains remain nearly constant until folding occurs.

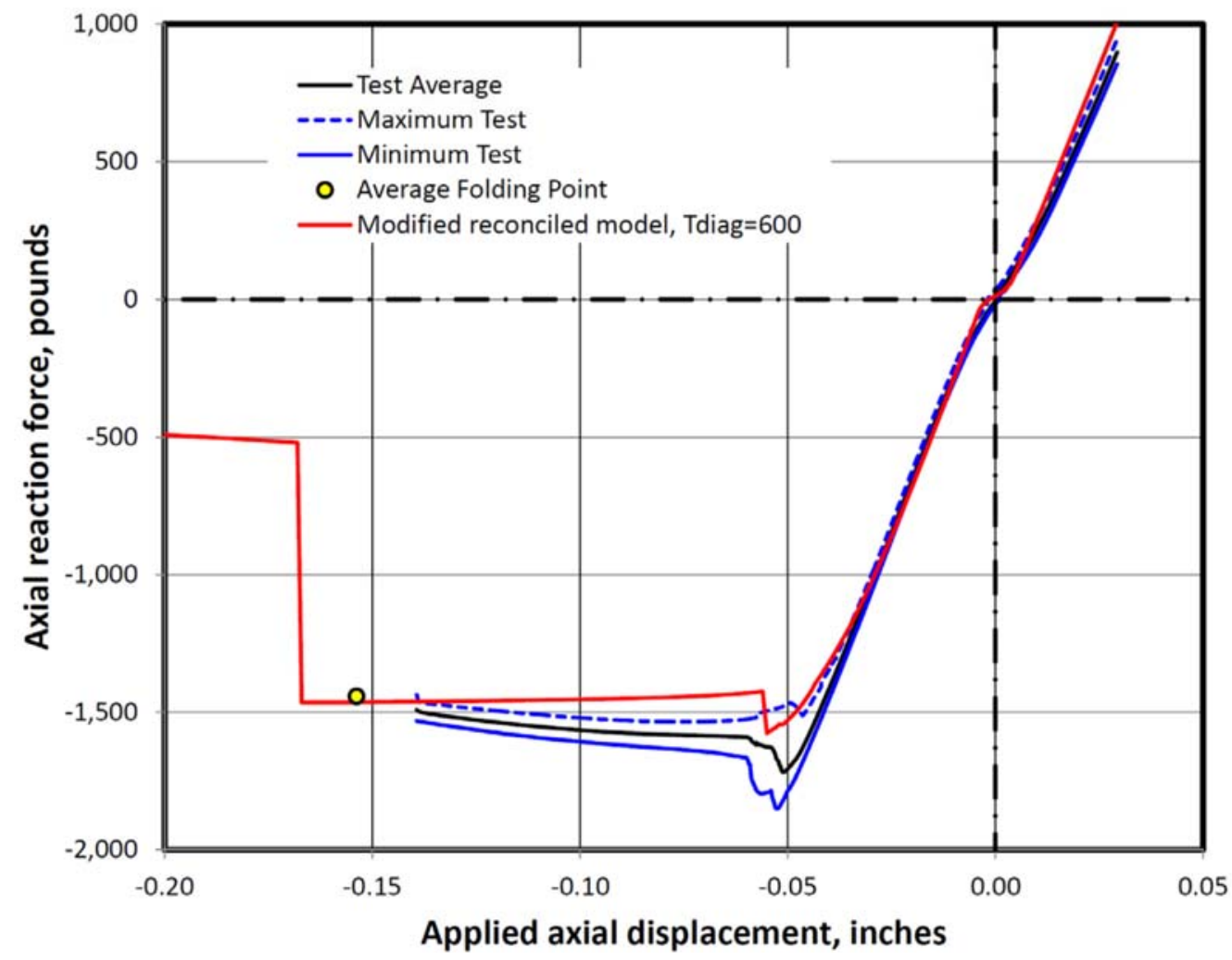

Figure 22. Test-analysis correlation for load versus end displacement for the single bay. 


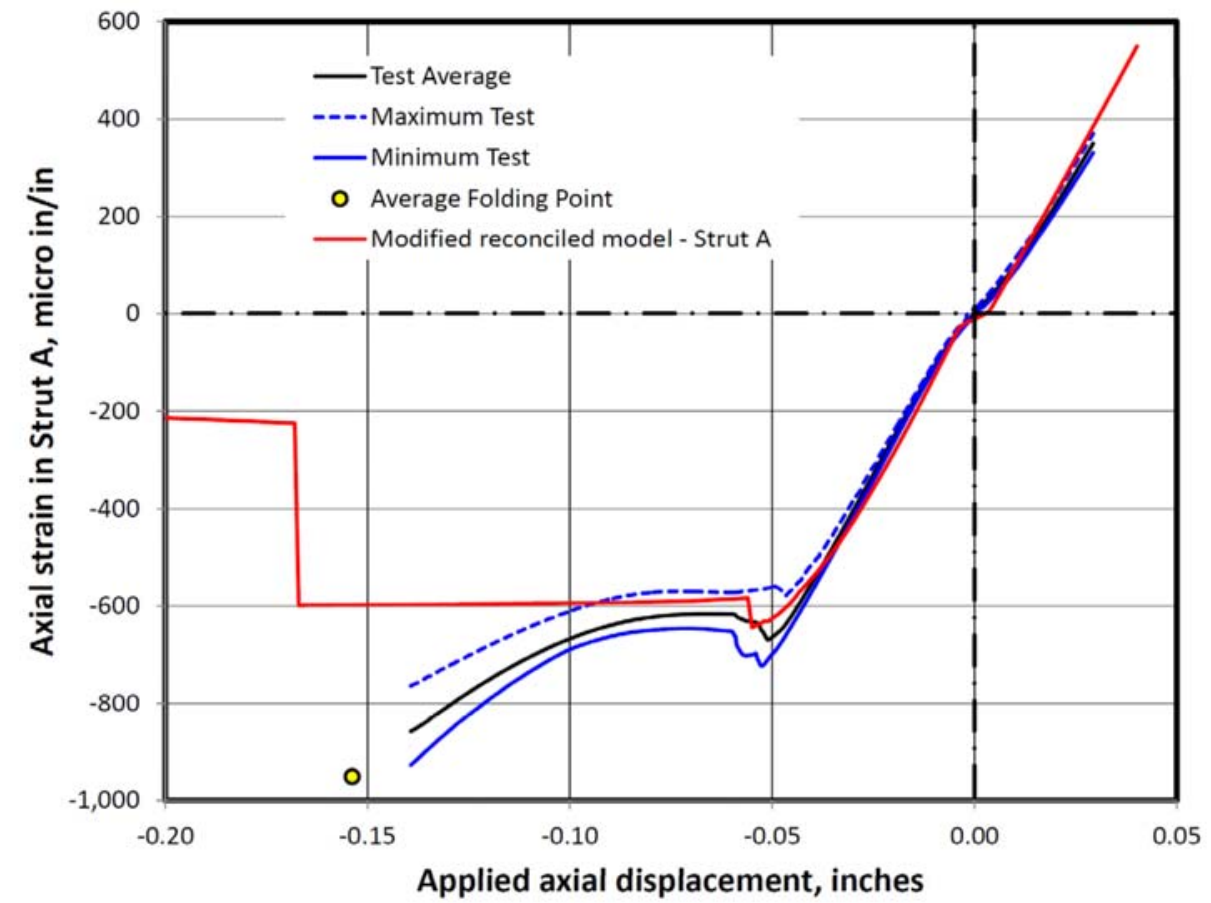

Figure 23. Axial strain in more buckled longeron versus end displacement for single bay.

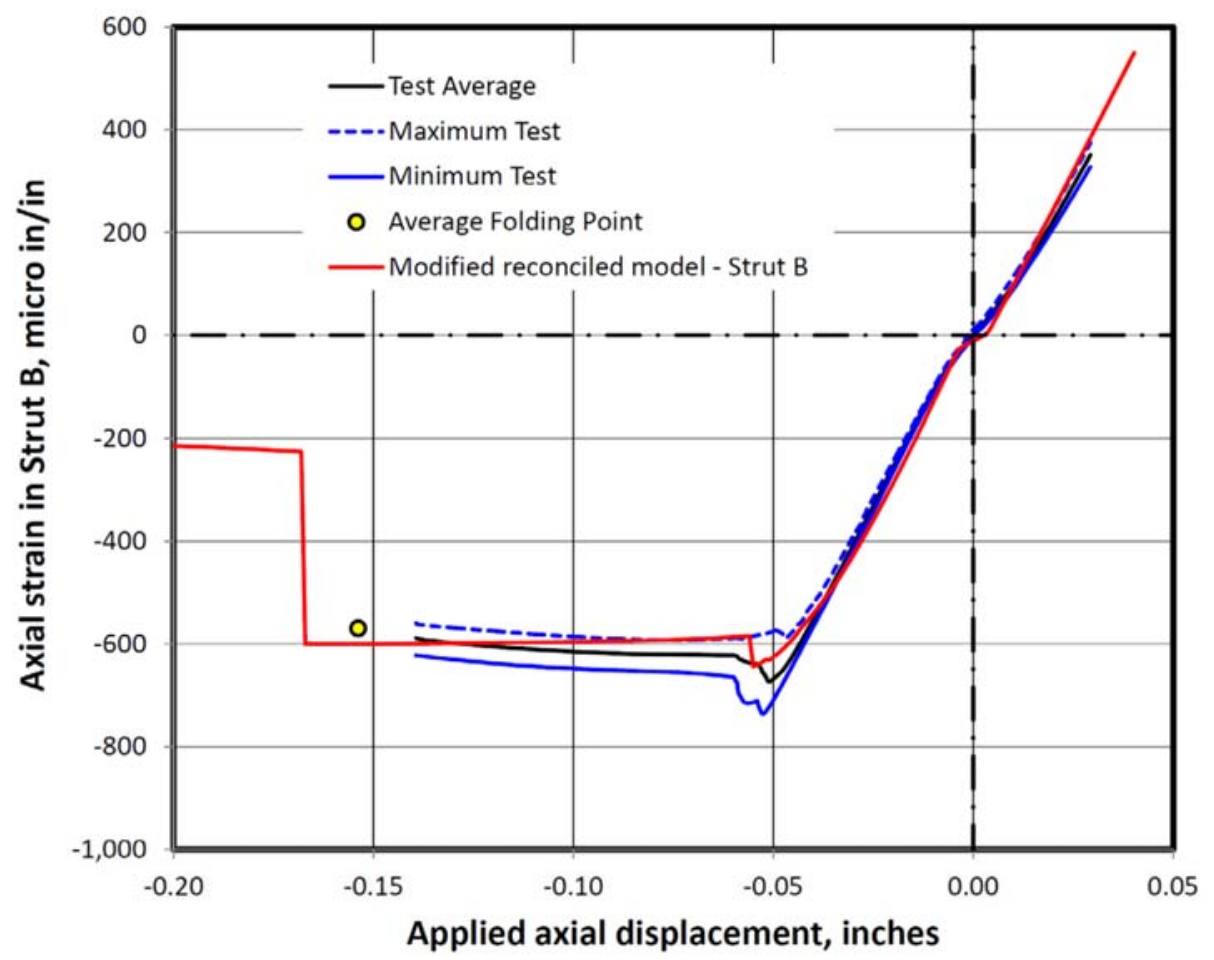

Figure 24. Axial strain in less buckled longeron versus end displacement for single bay.

American Institute of Aeronautics and Astronautics 


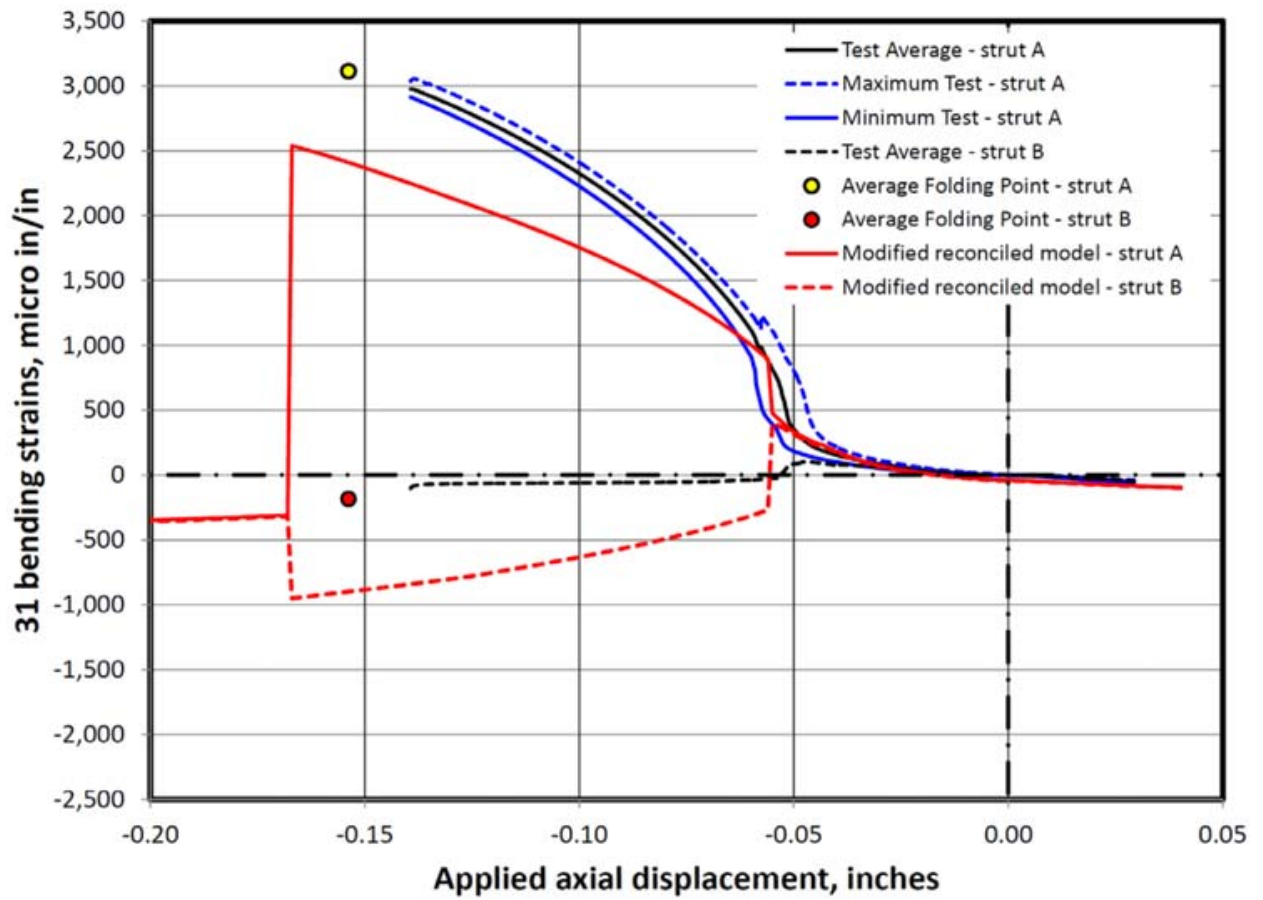

Figure 25. Primary 31 bending strain in both longerons versus end displacement for single bay.

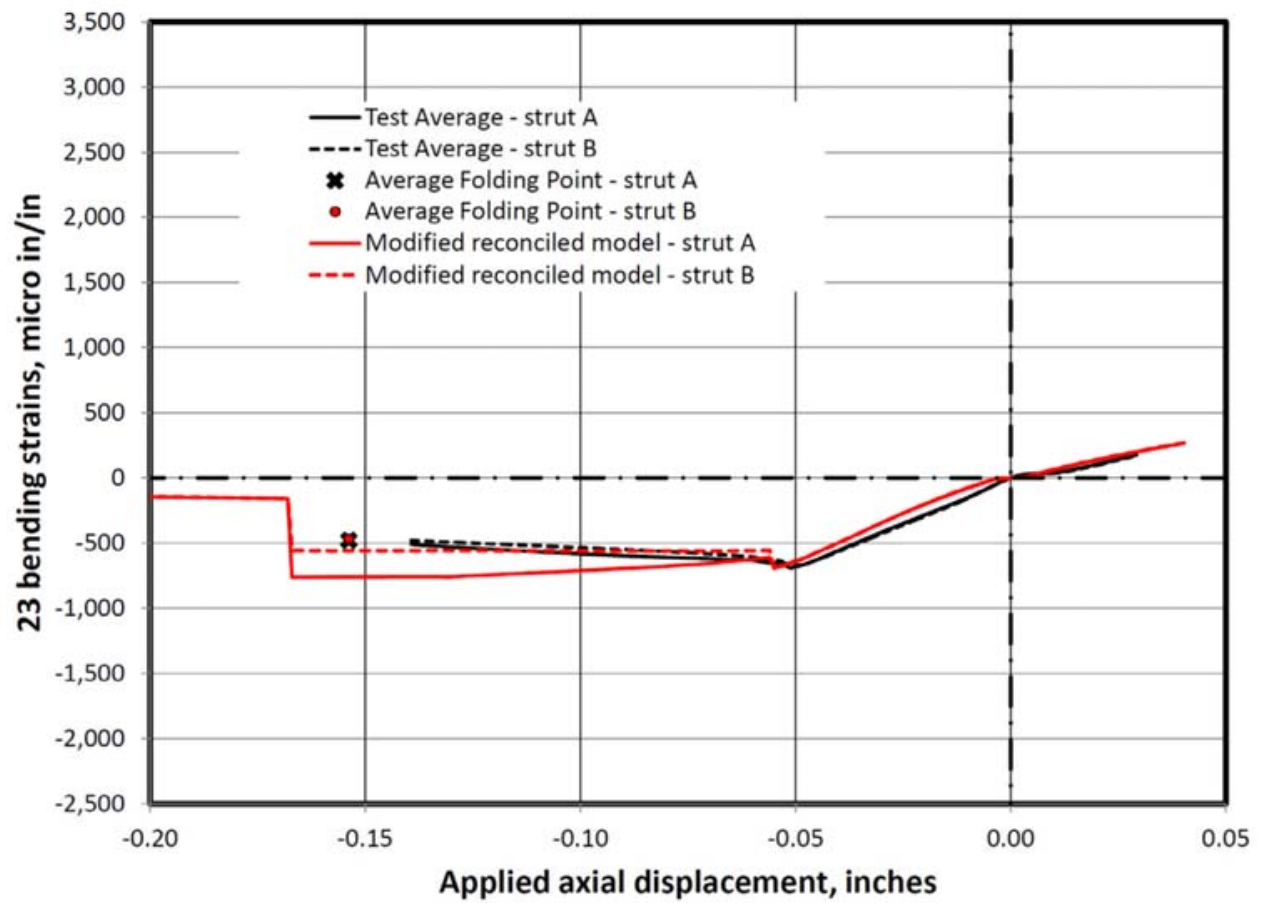

Figure 26. Secondary 23 bending strain in both longerons versus end displacement for single bay.

21

American Institute of Aeronautics and Astronautics 
At this point, the Nastran model using a modified set of the reconciled solution parameters predicts the average test response for the single bay having straight longerons. Two questions remain for the single bay models. One question relates to determining a new set of paramters for the single-bay model following the procedures established in Ref. 13. The second question relates to the observed inelastic response observed in Strut A of the single-bay test. The CBEAM element of MSC.Nastran ${ }^{\mathrm{TM}}$ is not able to represent through-the-thickness yielding - only plastic hinges. Therefore, the final Nastran ${ }^{\mathrm{TM}}$ model used for the single-bay simulations was converted to an Abaqus $^{\mathrm{TM}} /$ Standard ${ }^{19 * * * *}$ model that does provide for through-the-thickness elastic-plastic response. Preliminary Abaqus $^{\mathrm{TM}}$ results are shown as green curves in Figs. 27 through 29 indicating that local yielding does influence the response after buckling and in particular the axial strain in Strut A (the more buckled longeron). These findings indicate that parameter studies using Abaqus for the elastic-plastic prediction capability is warranted.

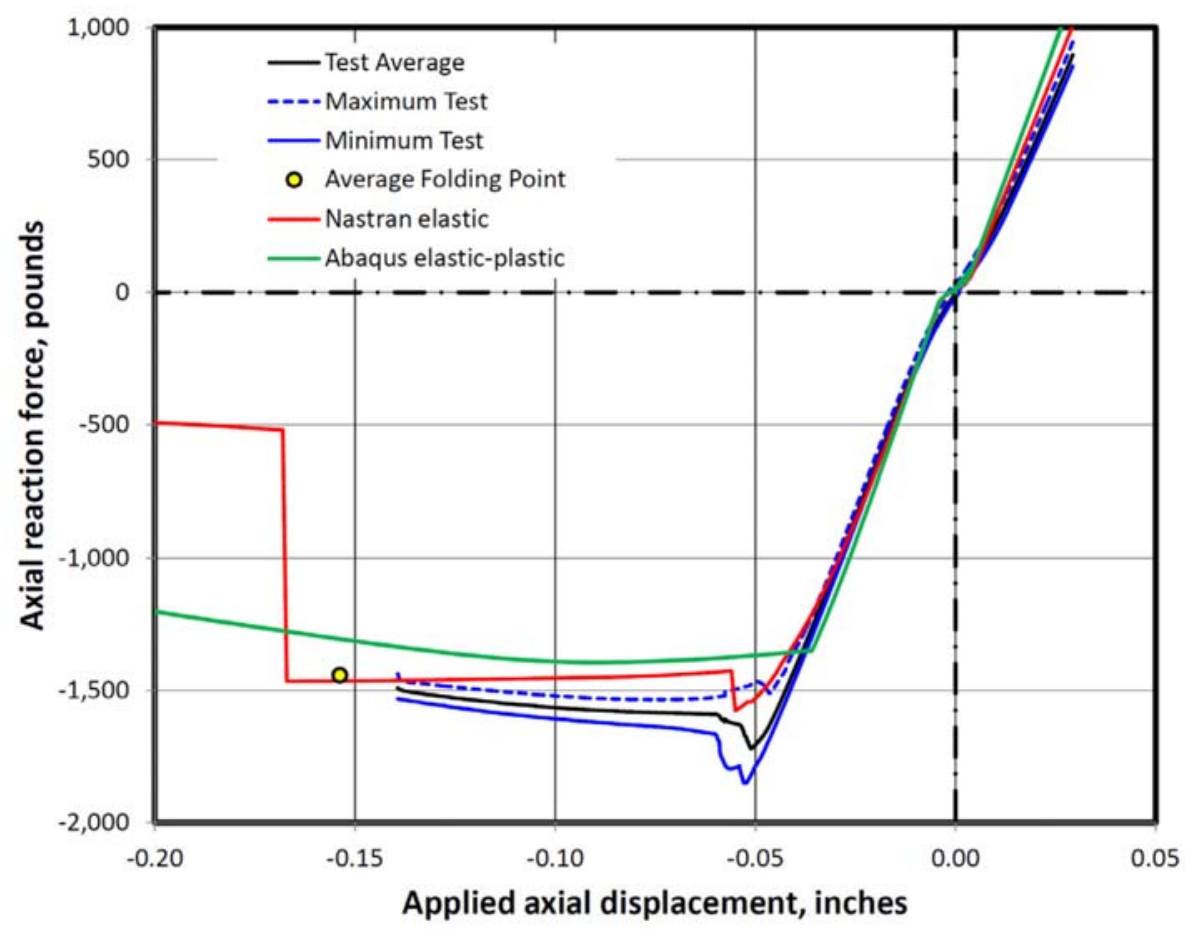

Figure 27. Comparison of the Nastran and Abaqus predictions for load versus end displacement for the single bay.

${ }^{* * * * * *}$ ABAQUS ${ }^{\mathrm{TM} / S t a n d a r d ~ i s ~ a ~ r e g i s t e r e d ~ t r a d e m a r k ~ o f ~ D a s s a u l t ~ S y s t e ̀ m e s ~ S i m u l i a ~ C o r p . ~}$

22

American Institute of Aeronautics and Astronautics 


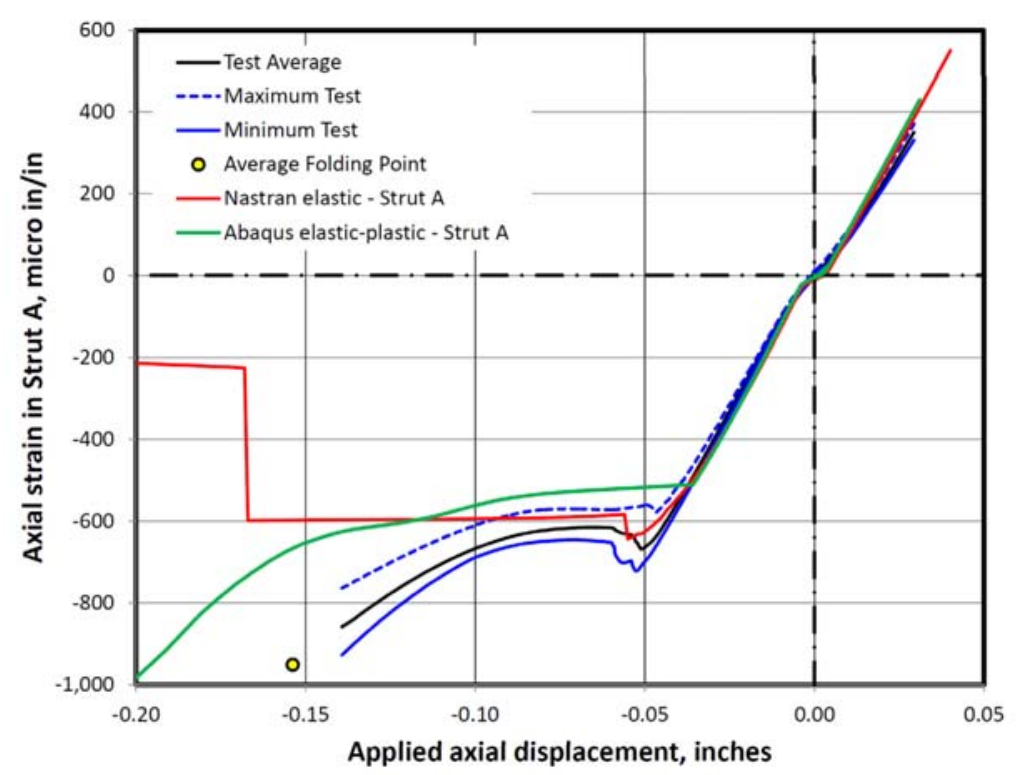

Figure 28. Comparison of the Nastran ${ }^{\mathrm{TM}}$ and Abaqus ${ }^{\mathrm{TM}}$ predictions for axial strain in Strut A versus end displacement for the single bay.

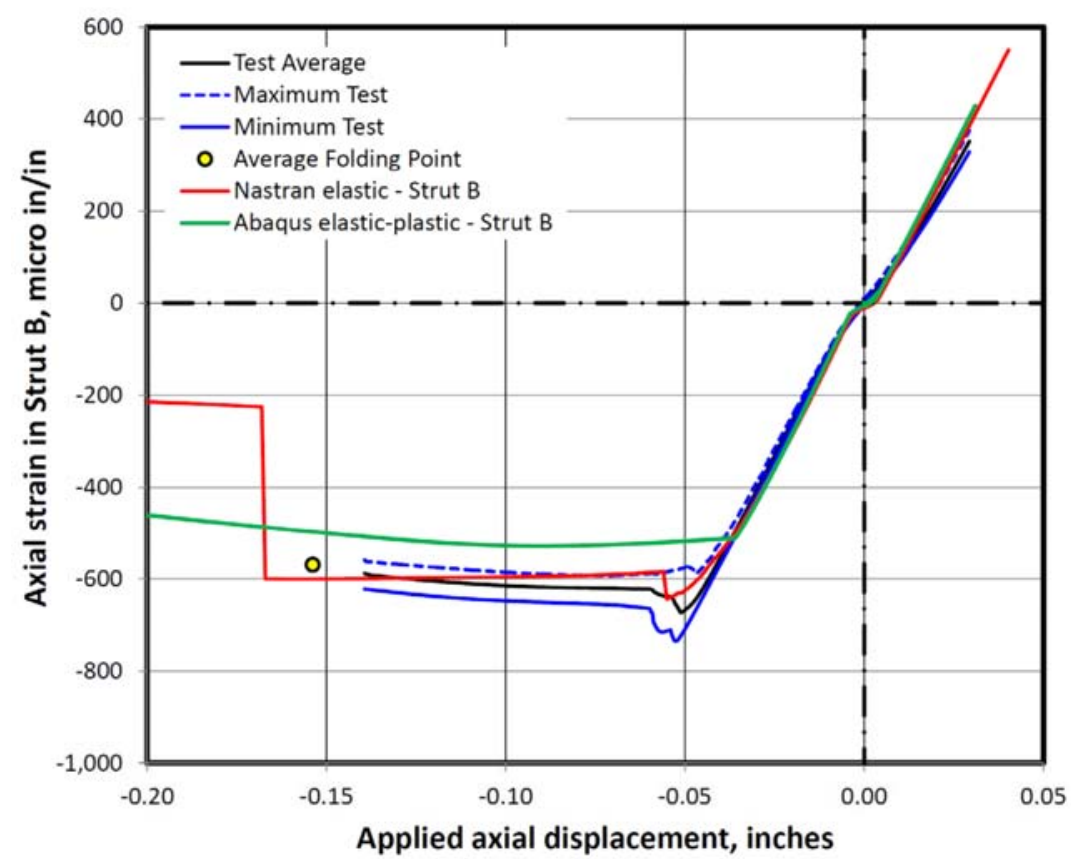

Figure 29. Comparison of the Nastran ${ }^{\mathrm{TM}}$ and Abaqus ${ }^{\mathrm{TM}}$ predictions for axial strain in Strut B versus end displacement for the single bay.

American Institute of Aeronautics and Astronautics 


\section{Concluding Remarks}

During routine ISS operations, it is possible for one or more longerons of a solar array wing mast to experience shadowing. The resulting thermal loads combined with mechanical loads have the potential to exceed design limits for the critical axial load. This paper describes the modeling and verification of models developed as predictive models to study the mast shadowing problem.

The finite element modeling approach used for a single-longeron and its end fittings extracted from the FAST mast 4-bay structural model as well as a single-bay model are described. The building-block approach used for modeling and analysis is illustrated. Different analysis tools can be used to predict the response accurately; however, subtle modeling details and element characteristics need to be examined when the finite element model of one tool is translated to the another.

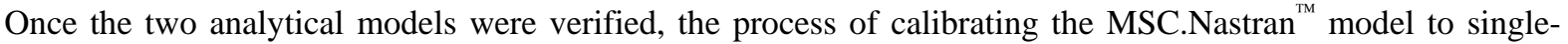
longeron test data was initiated. This process proved to be significantly more involved than first anticipated as discussed in Ref. 18. However, a set of parameters were identified that resulted in excellent test-analysis correlation for displacement and strain response metrics throughout the response up to buckling. This set of parameters is referred to as reconciled solution. It is believed that micro-slipping in the mechanical joints during testing prohibits a full correlation beyond initial buckling.

Using the single-longeron predictions, the single-bay models were updated to reflect the updated local geometry changed for load introduction as well as to incorporate the set of parameter values defined as the reconciled solution for the single-longeron effort. The modeling of the single bay introduced additional parameters that influence the structural response including member preload forces, different boundary conditions, nonlinear stiffness characteristics of the flex battens and diagonal cables, and the complexity of the structural response (buckling followed by folding). While the MSC.Nastran ${ }^{\mathrm{TM}}$ models correlated well with the single-bay average test data, uncertainties associated with the additional single-bay modeling parameters remain to be assessed. In addition, the elastic-plastic behavior of the straight longerons in the single-bay configuration required the further migration to Abaqus $^{\mathrm{TM}} /$ Standard. Preliminary Abaqus ${ }^{\mathrm{TM}}$ elastic-plastic predictions are in fair agreement with the measured test data using the parameter set defined for the MSC.Nastran ${ }^{\mathrm{TM}}$ model.

\section{References}

1. Bowden, M. L. and Woolery, B. K., "Space Station Solar Array Deployment Mast," Paper No. IAF-92-0697, $43^{\text {rd }}$ Congress of the International Astronautical Federation, August 28-September 5, 1992, Washington, DC.

2. Bowden, M. L. and Benton, M., "Design of Deployable-Truss Masts for Space Station,” AIAA Paper No. 930975, AIAA/AHS/ASEE Aerospace Design Conference, February 16-19, 1993, Irvine, CA.

3. Takeda, R., Robinson, S., Klein, S., Eacret, D., and Bowden, M., Mast-Canister Failure and Strength Assessment Final Report, Report No. AEC94518R921 Rev. A, AEC-Able Engineering Company, Goleta, CA, May 17, 1994.

4. Shaker, J. F., "Static Stability of a Three-Dimensional Space Truss," Proceedings of the $13^{\text {th }}$ Space Photovoltaic Research and Technology Conference (SPRAT-13), NASA Lewis Research Center, June 14-16, 1994, NASA CP-3728, pp. 299-312, September 1994.

5. Tang, C. C., Elliott, A. J., Bowden, M. L., and Robinson, S. "Static Test and Nonlinear Analysis of the Mast for International Space Station Alpha Solar Array Wing,” 1995 MSC World Users’ Conference, Paper No. 28, Universal City, CA, May 8-12, 1995.

6. Shaker, J. F., Static Stability of a Three-Dimensional Space Truss, NASA TM-106944, May 1995.

7. Shaker, J. F. and Acquaviva, T. H., Static Stability of the Space Station Solar Array FASTMast Structure, NASA TM-106895, August 1995.

24

American Institute of Aeronautics and Astronautics 
8. Pham, H. Q. and Slucter, J., ISS Solar Array Wing Mast Shadowing Thermal Vacuum Test Report, Jet Propulsion Laboratory, Report No. JPL-D-49526, January 15, 2009.

9. Pham, H. Q., ISS Solar Array Wing Mast Shadowing 32 Bay Thermal Model Report, Jet Propulsion Laboratory, Report No. JPL-D-61740, June 22, 2009.

10. Robinson, S. and Trautt, T., Solar Array Mast Buckling Analysis Report for the ISS Solar Array Mast, ATK Space Systems, Report No. 1163D3883, Rev. C, May 11, 2011.

11. Anon., ANSYS Mechanical, ANSYS Inc., 275 Technology Drive, Canonsburg, Pennsylvania 15317

12. Anon., Guide for Verification and Validation in Computational Solid Mechanics, ASME V\&V 10-2006, American Society of Mechanical Engineers, New York, 2006.

13. Elliott, K. B., Horta, L. G., Templeton, J. D., Knight, N. F., Jr., "Model Calibration Effort for the International Space Station's Solar Array Mast," AIAA Paper to be presented at the $53^{\text {rd }}$ AIAA/ASME/ASCE/AHS/ASC Structures, Structural Dynamics, and Materials Conference, Honolulu, HI, April 23-26, 2011.

14. Anon., MSC.Nastran ${ }^{T M} 2005$ Quick Reference Guide: Volume II, MSC.Software Corporation, 2005.

15. Anon., Composite Materials Handbook - Volume 3. Polymer Matrix Composites Materials Usage, Design, and Analysis, Department of Defense Handbook MIL-HDBK-17-3F, June 17, 2002.

16. Rouse, M., Jegley, D. C., McGowan, D. M., Bush, H. G., and Waters, W. A., "Utilization of Building-Block Approach in Structural Mechanics Research,” AIAA Paper No. 2005-1874, presented at the $46^{\text {th }}$ AIAA/ASME/ASCE/AHS/ASC Structures, Structural Dynamics, and Materials Conference, Austin, Texas, April 18-21, 2005.

17. Mohaghegh, M., "Validation and Certification of Aircraft Structures," AIAA Paper No. 2005-2162, presented at the $46^{\text {th }}$ AIAA/ASME/ASCE/AHS/ASC Structures, Structural Dynamics, and Materials Conference, Austin, Texas, April 18-21, 2005.

18. Knight, N. F., Jr., Nemeth, M. P., and Hilburger, M. W., Assessment of Technologies for the Space Shuttle External Tank Thermal Protection System and Recommendations for Technology Improvement - Part 2: Structural Analysis Technologies and Modeling Practices, NASA/TM-2004-213256, August 2004.

19. Anon., ABAQUS/Standard User's Manuals, Version 6.10. Dassault Systèmes Simulia Corp., Providence, Rhode Island, 2010.

20. Lake, M. S., Fung, J., Gloss, K., and Liechty, D. S., "Experimental Characterization of Hysteresis in a Revolute Joint for Precision Deployable Structures," AIAA Paper No. 97-1379, presented at the $38^{\text {th }}$ AIAA/ASME/ASCE/AHS/ASC Structures, Structural Dynamics, and Materials Conference, Kissimmee, Florida, April 7-10, 1997. 


\section{Appendix - FAST Mast Structural Components}

The purpose of this appendix is to describe various structural components and the modeling assumptions used for each of these FAST mast components.

\section{Longeron Clevis Ends}

The clevis ends of straight and tapered longerons are the identical and independent of the longeron configuration. The modeling approach here follows that originally developed by ATK and reported in Ref. 10. The modeling of the longeron clevis ends shown in Fig. A1 is briefly described in this section. First, the 'legs' of the clevis are modeled as separate beam elements with sectional properties related to each leg. The longeron pin (or axle) at the clevis end is located at the center of the pin hole in the clevis legs (see blue line in Fig. A1). The legs of the clevis are modeled using two beam elements having a separate property definition (or PID) value (i.e., PID=112 and 212 in Fig. A1). The tapered segment of the clevis end (between the legs and longeron square cross section) is modeled as two independent beam elements having the same sectional properties (i.e., $\mathrm{PID}=12$ ).

The longeron pins are modeled using beam elements where the torsional stiffness $\mathrm{J}$ is varied to simulate a 'free' or 'locked' pin condition. As this $\mathrm{J}$ value tends to zero, the clevis legs have little stiffness to resist rotation about the pin axis. Likewise, as the value of $\mathrm{J}$ increases, the clevis legs become increasingly stiff and resist rotation about the pin axis (i.e., they become 'locked'). Ideally, a nonlinear torsional spring element or a beam element that allowed a nonlinear elastic stress-strain curve for the torsional response should be used to simulate the response. In the current MSC.Nastran ${ }^{\mathrm{TM}}$ modeling approach, the longeron is either free to rotation (little resistance to twisting about the pin axis) or locked on the pin (significant resistance to twisting about the pin axis) for the entire simulation. In the hardware, it appears that a longeron pin is initially' locked' but may release and slip at higher load levels. Hence, the current modeling approach can only bound the response.

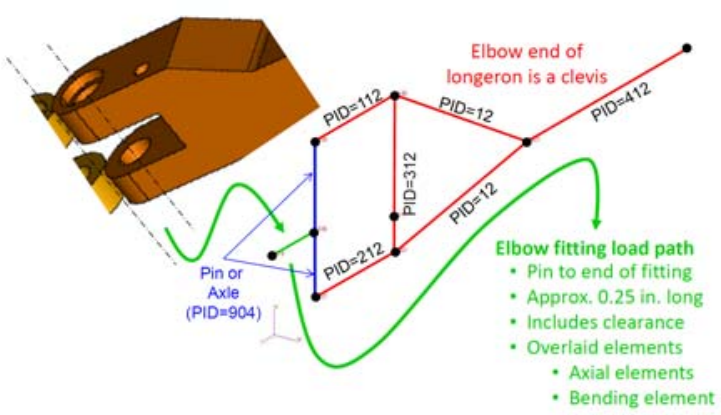

Figure A1. Modeling of typical longeron clevis end at elbow joints.

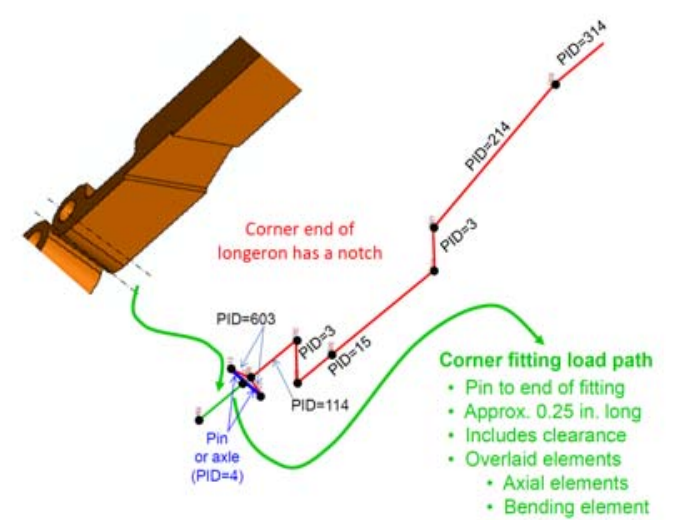

Figure A2. Modeling of typical longeron notched end at corner joints.

The distance between the centerline of the pin axis and the end of the clevis arms is 0.25 inches as indicated by the green line in Fig. A1. Part of this region represents the element of the clevis arms beyond the pin holes, and part of the region is potential clearances between the ends of adjacent longerons. This region of the clevis end is modeled using three overlaid elements: two rod elements and one beam element. This region is referred to as the elbow fitting load path model and is described further subsequently.

\section{Longeron Notched Ends}

The notched ends of straight and tapered longerons are the identical and independent of the longeron configuration. The modeling of the longeron notched ends shown in Fig. A2 is described in this section and again follows the approach originally reported in Ref. 10. The longeron ends at the corner joints have a significantly different configuration (i.e., notched versus clevis). The notched end is modeled using two 'stiff' beam elements to offset the notched segment of the longeron as shown in Fig. A2. The decision to use stiff beam elements rather than beams elements with offsets, or RBAR elements was based on the requirement that the modeling approach needed to be supported by the MSC.Nastran ${ }^{\mathrm{TM}}$ large-deflection analysis feature within SOL106. Three additional beam elements are used in the notched end model. One beam element extends between the pin and the edge of the 
notched segment. The second beam element has linearly varying sectional properties. The third beam element is also a tapered beam.

The next modeling assumption is related to the approach used to include the longeron pin. For the clevis end, the clevis legs provided a nature feature. For the notched end, a short 'stiff' clevis was included so that the longeron pin (blue line in Fig. A2) could be simulated. This pin is modeled in the same way as the pin in the clevis end. The distance between the centerline of the pin axis and the end of the clevis is 0.25 inches as indicated by the green line in Fig. A2. Part of this region represents the element of the longeron beyond the pin holes, and part of the region is potential clearances between the ends of adjacent longerons. Again, this region is modeled the same way as described previously for the clevis ends. This region is referred to as the corner fitting load path model and is discussed next.

\section{Corner and Elbow Fitting Load Path Modeling}

The load path modeling is assumed to be identical for both longeron ends; however, they are represented independently. The load path model represents the small 0.25-inch-long remnant of material on the longeron (i.e., from the center of the pin hole to the end of the longeron) as indicated in Figs. A1 and A2. The stiffness characteristics are typical of a revolute jointed system. ${ }^{20}$ The stiffness is bi-linear away from a zero load condition (different tension and compression stiffness values). Near the zero load state in Fig. A3, the stiffness is nonlinear. Ref. 20 shows that two types of nonlinearity are exhibited in a revolute joint. The first is free-play due to the pin/hole clearance in the joints. The second is a nonlinear stiffness due to the nonlinear contact developing between the pin and hole of the joints.

Decoupling the nonlinear contact stiffness from the joint free-play is not possible. However, the combined effect can be reported. For the purpose of this paper, the total effect of nonlinear contact stiffness combined with joint free-play is termed 'dead band'. The dead band is computed from the data (dotted blue curve in Fig. A3) as follows. The linear fit estimates of the response beyond $200 \mathrm{lb}$ tension and 200 lb compression (solid black lines) are extrapolated from $\pm 200 \mathrm{lb}$ back to the zero load condition (black dashed lines), as shown in Fig. A3. The distance between the compression and tension regression zero load intercepts is the total dead band shown on the figure and represents the total nonlinearity of the joint. The total dead band is also not centered at zero displacement. It is

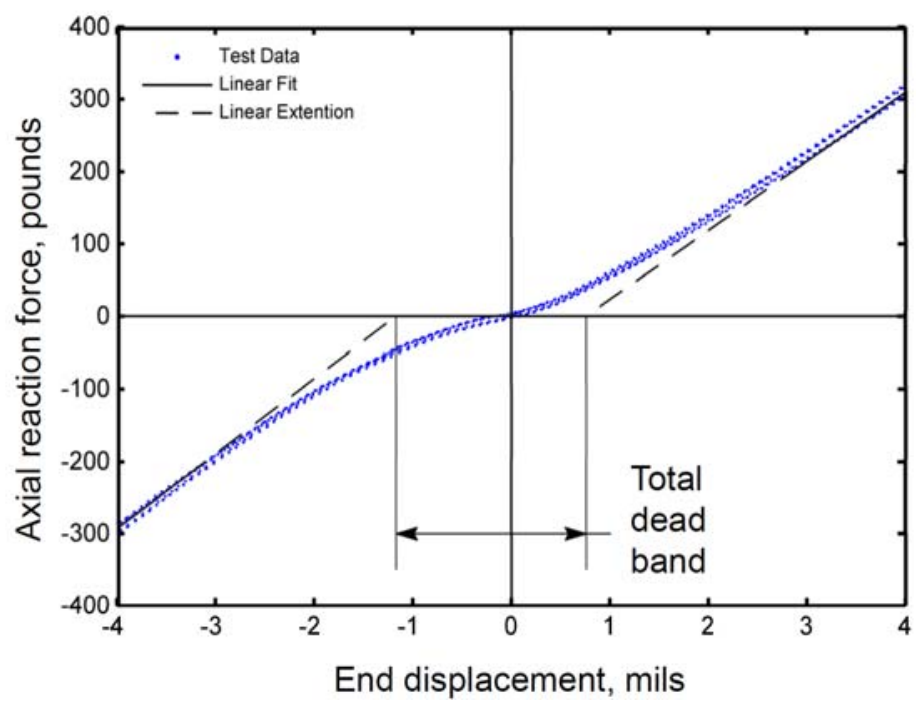

Figure A3. Representative single straight longeron dead band observations. skewed toward the compression side of the stiffness curve as indicated in Fig. A3. This bias could be due to actual physical behavior or to the test set-up. Only the linear free-play contributor is included in these finite element models based on one-dimensional spatial beam elements. There are two pin/hole gaps to consider for the single longeron test (elbow and corner fittings). In these models, the dead band is assumed to be equally distributed between the two pin/holes for each longeron but include a possible tension-compression bias.

A typical load path model at one end of a longeron has three overlaid elements: a single beam element and two rod elements. The beam element simulates any bending stiffness associated with this small remnant of material at the end of the longeron. The two rod elements represent the axial stiffness of the small remnant of material and the dead band for tension and compression - one element represents the tension dead band and one represents the compression dead band. The dead band values are converted into an initial strain using the rod element length of 0.25 inches. Each rod element has a nonlinear stiffness curve that includes a dead band, and each curve is defined by a MATS1 record associated with its material identification (MID) and TABLES1 records. These nonlinear curves have either zero tension stiffness and high compression stiffness after closing a specified initial gap or zero

27

American Institute of Aeronautics and Astronautics 
compression stiffness and high tension stiffness after closing a specified initial gap. Other modeling approaches, such as the use of CGAP elements proved to be unsuccessful because they were not supported for large deflection analyses within MSC.Nastran ${ }^{\mathrm{TM}}$ SOL106.

For a single longeron stiffness test simulation, corner and elbow load path models are present. For a given axial loading (say tension), the loaded end of the longeron will move through the tension dead band before loading the longeron. After the dead band at the loaded end is closed, then the dead band at the fixed end will begin the close as the longeron moves through the loaded end dead band. Once dead bands at both ends are closed, the longeron will begin to carry axial load. In the finite element model, it is assumed that the dead band values for tension and compression are equally divided between the corner and elbow load path models.

\section{Rigid Battens}

Each rigid batten has two 6061-T6 aluminum segments: a circular tube segment and a tapered C-shaped channel segment. Photographs of a representative rigid batten are shown in Fig. A4. An assembled and installed rigid batten is shown in Fig. A4a, and close-up photographs of the tapered channel section and the circular tube segment are shown in Figs. A4b and A4c, respectively. The open side of the channel segment faces outward away from the bay. Toward the center of the rigid batten at mid-bay, the channel segment transitions to a 0.5-inch-diameter solid

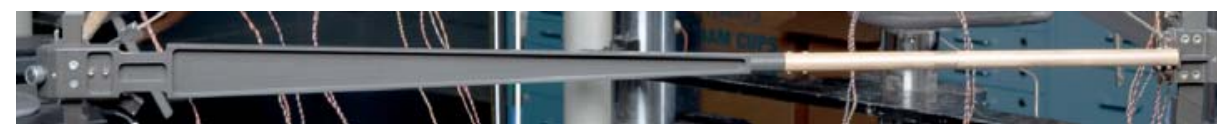

(a) Assembled two-piece rigid batten: tapered C-channel and circular tube.

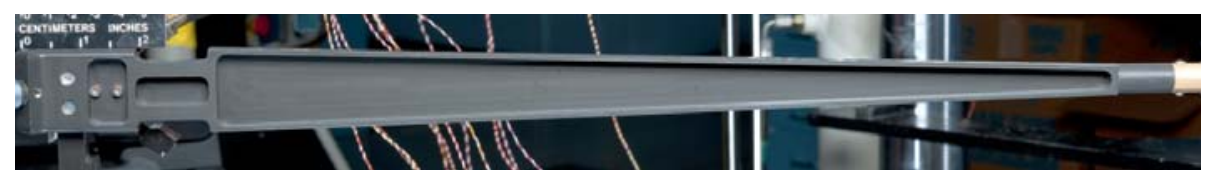

(b) Tapered C-shaped channel segment.

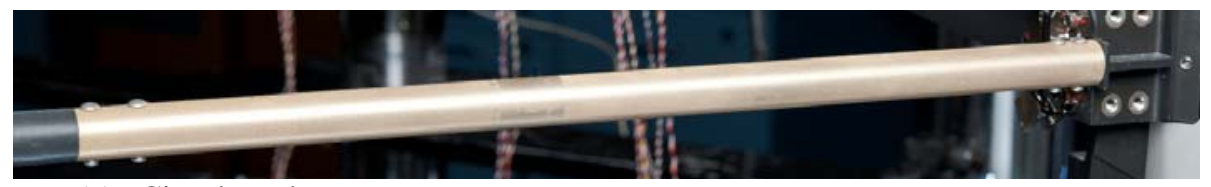

(c) Circular tube segment.

Figure A4. Photographs of a single rigid batten showing different cross-sectional segments.

circular rod and then to a slightly smaller diameter solid rod, 0.8 inches in length, that allows the hollow circular tube to fit over the smaller rod. At the corner fitting, the hollow circular tube segment also fits over a solid circular rod that extends 0.75 inches from the corner fitting. These batten components are referred to as 'rigid' battens, because they maintain the square cross-sectional shape of the mast while stowed, during deployment or retraction, and during normal in-space operations. These rigid battens are installed at the corner ends of a single bay and wrap around the longeron ends. The combined length of these two rigid batten components is 31.5 inches.

\section{Flex Battens}

The flexible or flex battens are installed at midlength of a single bay, and their locations within a bay are indicated in Fig. 4. The flex battens have a uniform 0.275-in. by 0.375-in. rectangular cross section with the larger cross-sectional dimension along the bay's longitudinal axis. Four flex battens are installed in each bay; one on each face. The flex battens are made from uniaxial S2 fiberglass/epoxy pultruded rods, and their length is somewhat longer than a typical bay side width of 30.4 inches. Once installed, these members are 'buckled' or bent slightly as a result of installation (see Fig. A1) and tend to lock the elbow joints in place once the bay is deployed. Each flex batten is buckled to a strain of $0.5 \%$ when fully deployed and $1.5 \%$ when stowed for a period of up to 7.5 years. ${ }^{3}$ In the deployed state, a flex batten is buckled or bowed outward about 1.75 inches as indicated in Fig. A5. 
The modeling approach for the flex batten follows the approach described in Ref. 5, and differs from the approach employed by ATK in their 4-bay model ${ }^{10}$. Within the MSC.Nastran model, each flex batten is modeled by overlaying a single rod element for its axial response only and a single beam element for the bending and torsional response - axial stiffness for the beam element is specified as zero. These two overlaid elements have coincident end nodes. This modeling approach eliminates the need to simulate the actual flex batten installation process that leads to the installed compressed 'bowed' configuration shown in Fig. A5. Thermal conditions (i.e., a non-physical temperature change to generate the preload) are specified to generate an initial compressive preload in the flex battens based on a nonlinear stress-strain curve for the axial response. The flex batten axial preload force varies from 45-50 pounds compression at beginning of life (i.e., the initial as-manufactured state) to 30-35 pounds compression at end of life (i.e., after long-term storage in a stowed state). The

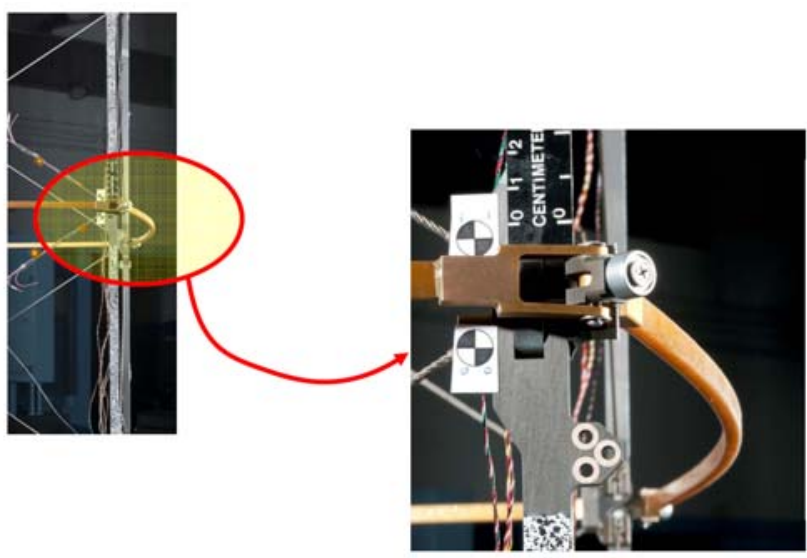

Figure A5. Photograph of a typical installed flex batten from a single-bay test article. bending response of the beam element is assumed to be linear elastic with an elastic modulus of 8 Msi to give the correct initial bending stiffness. The axial response of the rod element is assumed to be linear in tension and nonlinear in compression to simulate the postbuckled stiffness after installation. This postbuckled stiffness and preload is accomplished by specifying a thermal load in the flex batten rod elements and using measured axial force and end shortening displacements for an individual flex batten loaded in axial compression.

\section{Diagonal Cables}

Two diagonal cables are installed on each face of the upper and lower portions of a single bay as shown in Fig. 4. These cables are pre-strained stainless steel $7 \times 7$ wire ropes having about 30 pounds of tension preload each. A total of sixteen diagonal cables are installed in a single bay, and the length of each cable is somewhat shorter than a typical diagonal region of an upper or lower portion of a bay. Hence, these diagonal cables have a tension load that pulls on the elbow joint to keep it in a locked position once the bay is deployed. Each diagonal cable is modeled using a single rod element with an initial pre-tensioning accomplished using a specified thermal load for the element. A nonlinear stress-strain response is assumed for the tensile behavior of the cable based on measured force-deflection response., ${ }^{5,10}$ If compression is indicated, then a cable becomes 'slack' and does not transmit any compressive force.

\section{Mechanical Joints}

Mechanical joints connect longeron pairs at the corner ends and elbow ends. These mechanical joints are complex built-up assemblies. These mechanical joints and their corresponding connections with other structural members (e.g., diagonal cables, rigid battens, and flex battens) are described in the following sections. These joints are pinned longeron joints where rotation about the longeron pin is limited to one direction (i.e., the folding direction). These rotation limits are referred to as 'hard stops' for the joint motion. The finite element modeling approach and assumptions for these mechanical joints are summarized next.

\section{Corner Joints}

The corner joints are defined at the ends of a single bay and involve the notched ends of the longerons, the rigid battens, and the diagonal wires. The components of the corner joint and its assembly are shown in Fig. A6, and a photograph of a typical corner joint is shown in Fig. A7. The finite element modeling of these corner joints follows a similar the approach and procedure first presented in Ref. 10. The modeling of the notched ends of the longerons has been discussed previously for the straight and tapered longerons as well as for the lower and upper placement. At each corner joint, a rigid batten assembly is installed that has two components: a circular tube component shown in magenta in Fig. A6 and a tapered C-channel component shown in light green in Fig. A6. Notice that the end of the tapered C-channel component of the rigid batten wraps around the longeron ends to form a "J-shaped" segment that restricts the movement of the longeron joint. In representing this joint using one-dimensional rod and beam elements, rotational constraints caused by the wrap-around portion of the rigid batten (green members of the solid 
geometry model shown in Fig. A6) are simulated by 'hard stops' as originally described in Ref. 10. In addition, the diagonal wires and associated fittings are also installed as part of the corner joints. Each corner joint has four diagonal wire connections, and these diagonal wires impose a tension preload in the single bay. A typical corner joint assembly (slight re-oriented) and its finite element model are shown in Fig. A8.

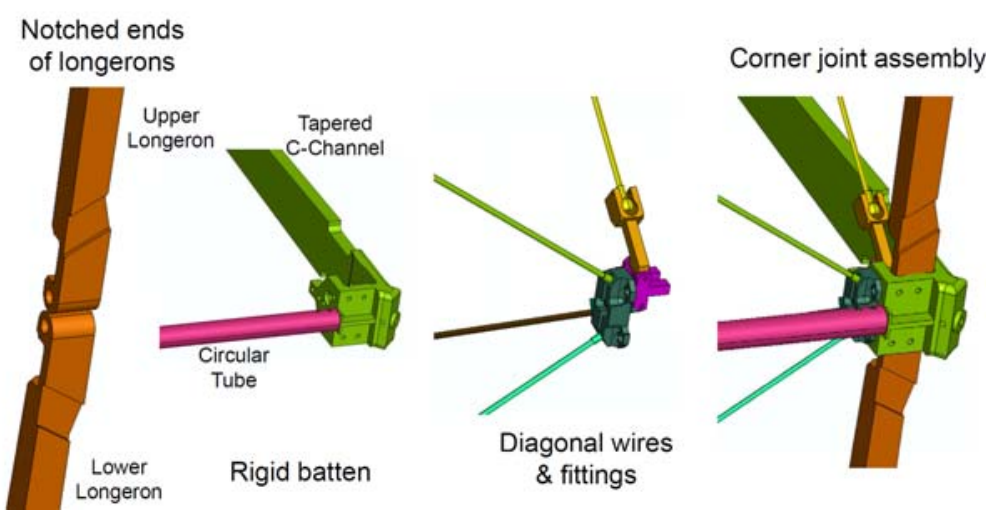

Figure A6. Typical corner joint and its assembly.

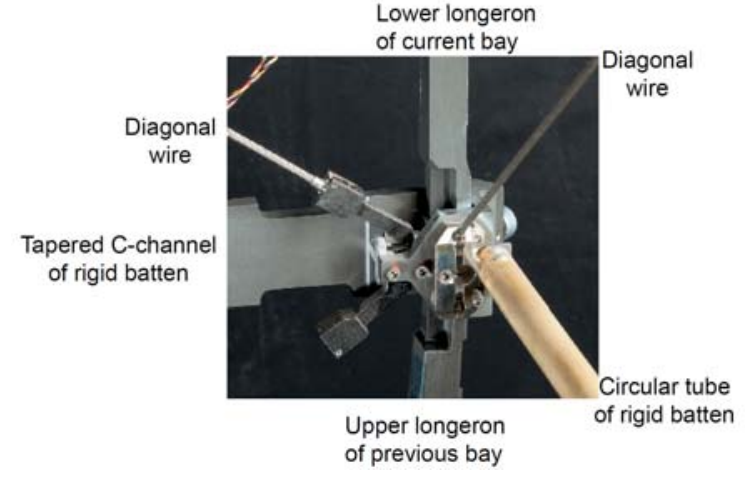

Figure A7. Photograph of typical corner joint in a single-bay test article.

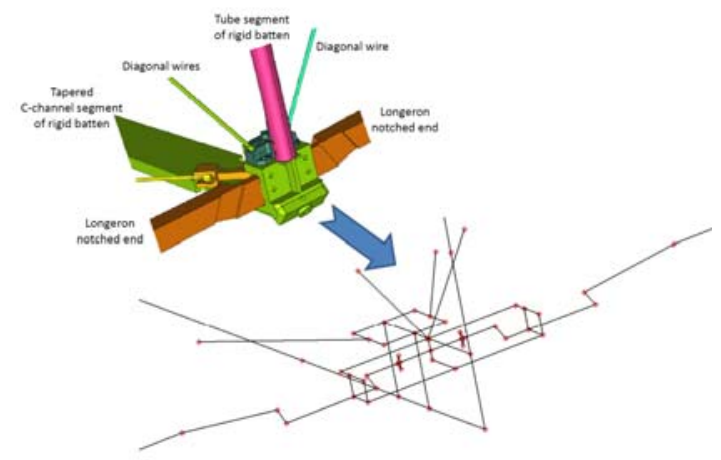

Figure A8. Typical corner joint assembly and finite element idealization. 


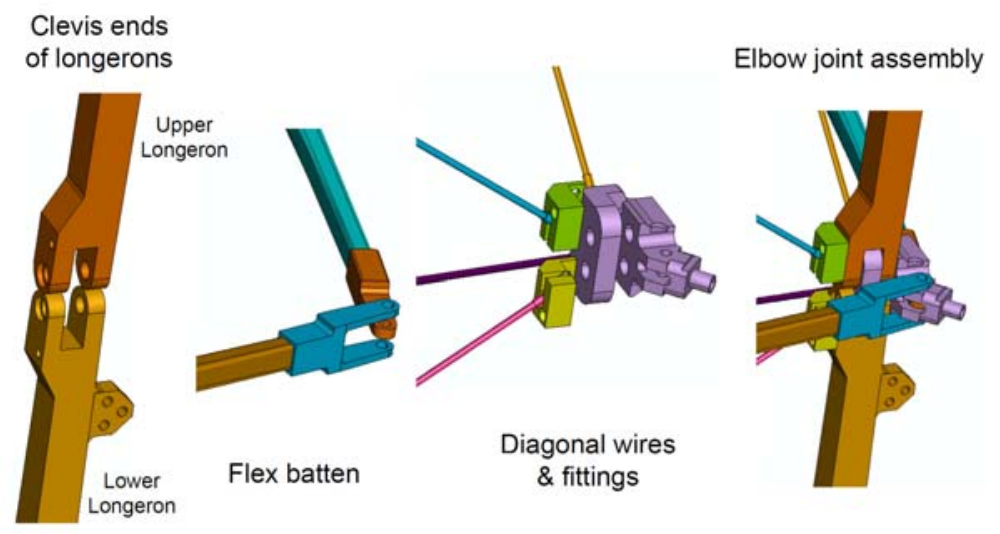

Figure A9. Typical elbow joint and its assembly.

\section{Elbow Joints}

The elbow joints are defined near mid-length of a single bay and involve the clevis ends of the longerons, flex battens, and diagonal wires. The components of elbow joint and its assembly are shown in Fig. A9, and a photograph of a typical elbow joint is shown in Fig. A10. The finite element modeling of these elbow joints follows the approach and procedure first presented in Ref. 10. At each elbow joint, a flex batten assembly is installed as shown in Fig. A9. Notice that the flex batten fitting (shown as light purple in Fig. A9) wraps around the longeron ends to form a U-shaped segment that restricts the movement of the longeron joint. In representing this joint using one-dimensional rod and beam elements, rotational constraints caused by the wrap-around portion of the flex batten fitting are simulated by 'hard stops' as originally described in Ref. 10. In addition, the diagonal wires and associated fittings are also installed as part of the elbow joints. Each elbow joint has four diagonal wire connections, and these diagonal wires impose a tension preload in the single bay. A typical elbow joint assembly (slightly reoriented in the figure) and its finite element model are shown in Fig. A11.

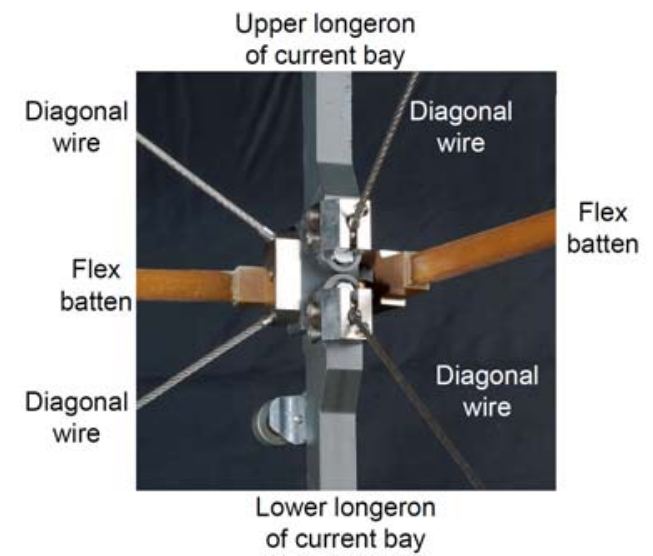

Figure A10. Photograph of typical elbow joint in a single-bay test article.

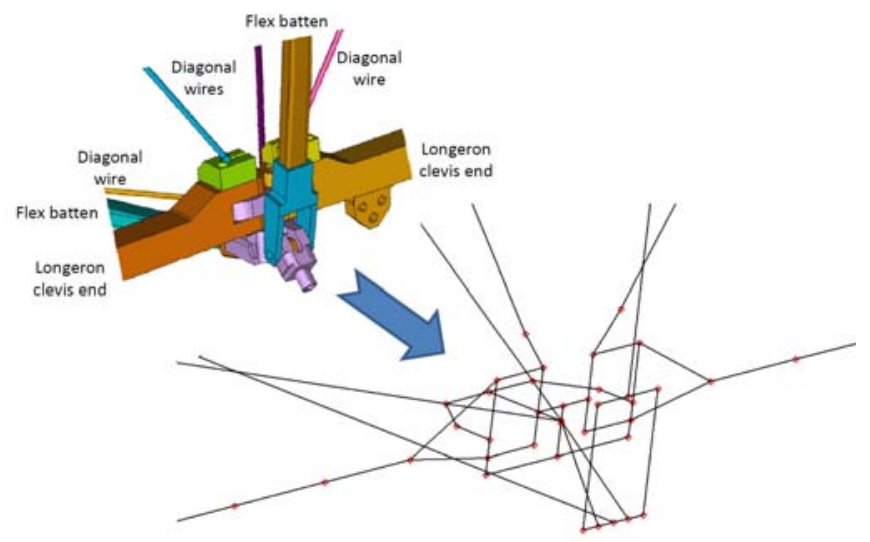

Figure A11. Typical elbow joint assembly and finite element idealization. 